\title{
Ciliary Generation of a Peptidergic Sexual Signal
}

From the ${ }^{1}$ Department of Molecular Biology and Biophysics, and ${ }^{2}$ Department of Neuroscience, University of Connecticut Health Center, 263 Farmington Avenue, Farmington, Connecticut 06030-3305, USA.

* Address correspondence to BAE (eipper@uchc.edu) or SMK (king@uchc.edu)

ORCID Numbers: 0000-0003-1554-0723 (RL), 0000-0003-1154-1331 (REM), 0000-0003-1171-5557 (BAE), 0000-0002-5484-5530 (SMK)

8 Running Title: Peptidergic signaling through cilia

Key Words: Amidation / Chlamydomonas / Cilia / Chemotaxis / Peptidergic signaling

\section{Abstract}

Peptidergic intercellular communication occurs throughout the eukaryotes, and regulates a wide range of physiological and behavioral responses. Cilia are sensory and secretory organelles that both receive information from the environment and transmit signals. Cilia derived vesicles (ectosomes), formed by outward budding of the ciliary membrane, carry enzymes and other bioactive products; this process represents an ancient mode of regulated secretion. Our previous study revealed the presence of the peptide amidating enzyme, peptidylglycine $\alpha$-amidating monooxygenase (PAM), in cilia and its key role in ciliogenesis. Furthermore, PAM and its amidated products are released in ciliary ectosomes from the green alga Chlamydomonas reinhardtii. One amidated product (GATI-amide) serves as a chemotactic modulator for $C$. reinhardtii gametes, attracting minus gametes while repelling plus gametes. Here we dissect the complex processing pathway that leads to formation of this amidated peptidergic sexual signal specifically on the ectosomes of plus gametes. We also identify a potential prohormone convertase that undergoes domain rearrangement during ectosomal secretion as a substrate for PAM. Analysis of this pathway affords insight into how single-celled organisms lacking dense core vesicles engage in regulated secretion, and provides a paradigm for understanding how amidated peptides that transmit sexual and other signals through cilia are generated.

\section{Introduction}

Cilia are membrane-delimited, microtubule-based cell extensions that protrude into the extracellular space and function as key motile, sensory and secretory organelles in many eukaryotes (Marshall and Basto, 2017). These complex organelles that were present in the last eukaryotic common ancestor both receive and transmit signals (Carvalho-Santos et al., 2011; Malicki and Johnson, 2017). Proteins encoded by approximately $5 \%$ of the human genome contribute to their assembly, structure and function (van Dam et al., 2019). Mutations in many of these genes cause ciliopathies, with phenotypes ranging from neurological malformations, skeletal abnormalities and kidney disease to obesity and insulin resistance (Reiter and Leroux, 2017). The ciliary localization of receptors for peptides such as Wnt, Hedgehog, insulin, somatostatin and $\alpha$-melanocyte stimulating hormone ( $\alpha \mathrm{MSH})$ plays an essential role in their signaling ability (Anvarian et al., 2019; Green et al., 2016; Wang et al., 2021). 
The biosynthesis of signaling peptides involves a well-described sequence of post-translational modifications and proteolytic cleavages that occur as the preproproteins transit from their site of synthesis in the lumen of the endoplasmic reticulum (ER) to the Golgi complex, and are packaged for secretion. Post-translational modifications including disulfide bond formation, $\mathrm{N}$ - and O-glycosylation, lipidation, endo- and exo-proteolysis are often required and must occur before secretion (Matsubayashi, 2011; Yasuda et al., 2013). Peptidylglycine $\alpha$-amidating monooxygenase (PAM), an ancient copperdependent monooxygenase, catalyzes the final step in the biosynthesis of a broad array of peptides such as mammalian $\alpha \mathrm{MSH}$ and vasopressin, the sea urchin sperm attractant resact, as well as numerous invertebrate venom peptide toxins. Amidation occurs via a two-step reaction catalyzed by the sequential actions of the monooxygenase (peptidylglycine $\alpha$-hydroxylating monooxygenase; PHM) and lyase (peptidyl- $\alpha$-hydroxyglycine $\alpha$-amidating lyase; PAL) catalytic cores of PAM (Luxmi et al., 2021).

Studies in Chlamydomonas reinhardtii, a chlorophyte green alga, revealed the presence of active PAM in the ciliary membrane and demonstrated its key role in ciliogenesis. The ciliary localization of PAM is conserved in mammals, and a role for PAM in ciliary formation and maintenance is observed in mice, zebrafish and planaria (Kumar et al., 2016a; Kumar, 2017; Kumar et al., 2018). Although the catalytic activity of PAM plays an essential role supporting ciliogenesis, how an enzyme essential for a final step in the biosynthesis of secreted peptides contributes to ciliogenesis remains unclear.

C. reinhardtii has served as a key model organism for dissecting ciliary assembly, function and signaling (Kumar et al., 2019; Sasso et al., 2018). Although secretory granules that store bioactive peptides in neurons and endocrine cells are not observed, we searched for evidence that $C$. reinhardtii produces and secretes amidated peptides. In addition to constitutive secretion of soluble cargo from Golgi-derived vesicles, the cilia of $C$. reinhardtii shed extracellular vesicles (ectosomes) produced by outward budding from the ciliary membrane (Cao et al., 2015; Long and Huang, 2020; Wang et al., 2014; Wood et al., 2013). Ectosomes released from the cilia of vegetative cells are bioactive and contain a subtilisin-like endoprotease (VLE1) that degrades the mother cell wall (Kubo et al., 2009; Long et al., 2016; Wood et al., 2013). Under plentiful nutrient conditions, haploid C. reinhardtii cells divide by mitosis. Starvation triggers a genetically encoded developmental process resulting in the formation of sexual gametes of opposite mating type (termed minus and plus). Ectosome release increases rapidly when minus and plus gametes are mixed (Cao et al., 2015). The interaction of their cilia triggers a complex intraciliary signaling pathway that leads to loss of gametic cell walls, formation of mating structures, and cell fusion, yielding a quadriciliate cell that ultimately develops into a diploid zygote. When nutrient conditions improve, the zygote hatches, releasing haploid meiotic progeny (Harris, 2009).

Mass spectrometric analysis of mating ciliary ectosomes led to the identification of an amidated peptide, derived from Cre03.g204500, that acts as a chemotactic modulator, attracting minus gametes while repelling plus gametes (Luxmi et al., 2019). Amidated peptides from echinoderms, Hydra, vespids and humans have also been reported to induce chemotaxis (Palma, 2006; Rowe and Elphick, 2012; Szabó et al., 2015; Takahashi et al., 1997). Cre03.g204500 encodes a 93-kDa protein with all of the features expected of a prepropeptide (hereafter referred to as preproGATI) (Luxmi et al., 2019). Acting on the proprotein (proGATI) created by removal of the signal sequence, a carboxypeptidase B-like enzyme could remove three Arg residues, thus generating a substrate for PAM and production of an amidated C- 
The $C$. reinhardtii genome encodes many proteins with the characteristics of prepropeptides. Mating ciliary ectosomes contain proteins derived from several of these prepropeptides, along with the subtilisinlike enzymes needed for their cleavage, PAM and multiple amidated products (Luxmi et al., 2019). Cterminal amidation is often required for peptide bioactivity, as it can greatly enhance affinity for the cognate receptor and confers resistance to proteolytic degradation (Luxmi et al., 2021). Our data suggest that the mating type-specific production and release of bioactive products in ciliary ectosomes represent an evolutionarily ancient path to achieving their regulated secretion.

Here we define the complex processing and amidation pathway leading to formation of the C. reinhardtii chemotactic sexual signal and determine how it is trafficked through cilia and ultimately released into ciliary ectosomes and the soluble secretome. We also find that one potential ciliary-localized prohormone convertase is itself a PAM substrate and undergoes an alteration in domain organization during ciliary trafficking, coincident with release of the peptidergic sexual signal. Analysis of proGATI, which yields bioactive products, provides a route to understanding how regulated secretion can occur in a single celled organism lacking peptide storage vesicles. As PAM, peptide processing enzymes, and cilia are broadly conserved in eukaryotes, this study provides a paradigm for understanding how amidated products that transmit chemotactic sexual and other signals through cilia can be generated.

\section{Results}

\section{Mating ectosomes contain proGATI along with $\mathrm{N}$-terminal and C-terminal fragments of proGATI}

Tryptic peptides derived from preproGATI, the protein encoded by Cre03.g204500 and consisting of 908 residues, were identified in both mating ectosomes and the soluble secretome (Luxmi et al., 2018; Luxmi et al., 2019). Interestingly, a proGATI peptide that had been $\alpha$-amidated and terminated with the sequence-Gly-Ala-Thr-Ile-amide (GATI-amide) was identified in mating ectosomes (Luxmi et al., 2019) and in one of six secretome samples analyzed previously (Luxmi et al., 2018). Removal of the N-terminal signal sequence from preproGATI would yield proGATI, with a calculated molecular mass of $90.6 \mathrm{kDa}$. The amidation of proGATI requires the removal of three Arg residues by a carboxypeptidase B-like exoprotease (Fig. 1A), generating a Gly-extended protein that can serve as a PAM substrate; following $\alpha$ hydroxylation of this Gly residue by PHM, PAL-mediated cleavage produces a protein terminating with a C-terminal Ile-amide (Fig. 1A).

To explore the biosynthesis, post-translational processing, trafficking and secretion of products generated by the endoproteolytic cleavage of proGATI, we prepared antibodies to a synthetic peptide located near its $\mathrm{N}$-terminus ( $\mathrm{N}$-ter peptide) and to a peptide that included the amidated $\mathrm{C}$-terminus (C-ter peptide) (Fig. 1A). Three rabbits were injected with a mixture of carrier-conjugated synthetic peptides and mating ectosomes were used to evaluate the sera. Bands of similar apparent molecular mass were visualized in varying amounts by all three sera; the most prominent appeared at $\sim 250 \mathrm{kDa}, \sim 120 \mathrm{kDa}, \sim 75 \mathrm{kDa}$ and $\sim 63$ kDa (Fig. 1B); post-translational modifications such as $\mathrm{N}$-glycosylation and O-glycosylation can have a dramatic effect on the apparent molecular mass of proteins (Bollig et al., 2007; Voigt et al., 2007). 
kDa signal (Fig. 1B). The ability of both peptides to block the appearance of the 250-kDa band suggests that it is an extensively modified form of proGATI. The presence of multiple smaller products indicates that proGATI is subjected to endoproteolytic cleavage.

To determine if the signal produced by the C-ter antibody required amidation, serum was pre-incubated with the amidated C-ter peptide (GATI-NH $\mathrm{NH}_{2}$ ), the Gly-extended peptide (GATI-Gly) or GATI-OH, which has a free carboxyl group at its C-terminus (Fig. 1C). For both the 250-kDa proGATI band and the 75-kDa band, the signal was greatly reduced by pre-incubation with the GATI- $\mathrm{NH}_{2}$ peptide, partially attenuated by preincubation with the GATI-Gly peptide and unaffected by the GATI-OH peptide. These data indicate that at least a fraction of the 250-kDa proGATI and 75-kDa product in mating ectosomes is amidated (Fig. 1C).

Affinity-purification was used to prepare antibodies that recognized either the $\mathrm{N}$-terminal region or the amidated C-terminus of proGATI. In agreement with the peptide blocking experiments, affinity-purified $\mathrm{N}$-ter antibody recognized the $250-\mathrm{kDa}, 120-\mathrm{kDa}$ and $63-\mathrm{kDa}$ bands in mating ectosomes while C-ter antibody affinity-purified using the GATI- $\mathrm{NH}_{2}$ peptide recognized the 250-kDa and 75-kDa bands (Fig. S1A). The specificity of the affinity-purified antibodies was quantified using solid phase assays (Figs. S1B and C).

These data suggest that the $250-\mathrm{kDa}$ protein visualized by both antibodies is a heavily modified version of proGATI, a significant fraction of which is $\alpha$-amidated. Endoproteolytic cleavage could generate an amidated 75-kDa C-ter fragment along with a 120-kDa N-ter fragment. An additional cleavage could yield a 63-kDa N-ter fragment along with a fragment that would not be recognized by either antibody.

136 Endoproteolytic cleavage of proGATI generates a heavily glycosylated $75 \mathrm{kDa}$ product that contains the 137 amidated chemomodulatory peptide.

138 We next used mass spectrometry to identify the proGATI region included in the amidated 75-kDa C-ter fragment immunoprecipitated from mating ectosomes (Fig. 1D). Analysis of in-gel tryptic digests revealed its complete C-terminal amidation. The other tryptic peptides identified provided almost complete (79.7\%) coverage of the region from a candidate furin-like cleavage site $\left(\mathrm{R}^{693} \mathrm{FSR}\right)$ to $11 \mathrm{e}^{904}-\mathrm{NH}_{2}$, the amidated $\mathrm{C}$-terminus of the chemomodulatory peptide. The calculated polypeptide mass of this cleavage product is $23 \mathrm{kDa}$ (Fig. 1E and F).

144 Amongst the post-translational modifications that could generate a 23-kDa C-ter proGATI protein 145 backbone with an apparent molecular mass of $75 \mathrm{kDa}$ are $\mathrm{N}$ - and $\mathrm{O}$-glycosylation. As in all eukaryotes, $146 \mathrm{~N}$-glycosylation in $\mathrm{C}$. reinhardtii involves the assembly of a lipid-linked oligosaccharide that is transferred 147 to target Asn residues in the lumen of the ER followed by maturation in the Golgi complex (Mathieu-Rivet et al., 2020). However, lacking several of the enzymes required for the synthesis of a canonical lipid-linked oligosaccharide, C. reinhardtii N-glycans have a unique core structure (Mathieu-Rivet et al., 2020). Two Nglycosylation sites are predicted in this polypeptide using the NetNGlyc tool (Fig. 1E and F). While most of the O-glycans identified in mammals are attached to Ser or Thr residues, in C. reinhardtii they are more often attached to hydroxyproline (HyP) residues (Bollig et al., 2007; Joshi et al., 2018; Mathieu-Rivet et S1D). 
Treatment of mating ectosomes with PNGase $\mathrm{F}$, which removes many mammalian $\mathrm{N}$-linked sugars, reduced the apparent molecular mass of a small fraction of the 75-kDa product detected by the C-ter antibody (Fig. S1E); treatment with an O-glycosidase/neuraminidase cocktail was without effect. The mobility of the 120-kDa proGATI fragment recognized by the $\mathrm{N}$-ter antibody was unaltered by either treatment (Fig. S1E). The non-canonical lipid-linked oligosaccharide identified in C. reinhardtii, along with its lack of $\mathrm{N}$-acetylglucosaminyltransferase $\mathrm{I}$, which is required for maturation of $\mathrm{N}$-linked oligosaccharides, likely compromise the efficacy of PNGase F; the unique composition of $C$. reinhardtii Oglycans would limit the efficacy of the O-glycosidase cocktail used (Joshi et al., 2018; Mathieu-Rivet et al., 2020).

\section{HEK-293 cells synthesize and secrete heavily glycosylated, amidated proGATI}

To facilitate our understanding of the proGATI protein and the modifications involved in producing the amidated $75 \mathrm{kD}$ a protein secreted in mating ectosomes, we stably expressed a cDNA encoding preproGATI in a human embryonic kidney cell line (HEK-293). In C. reinhardtii, as in other species, maturation of newly synthesized glycoproteins and their ability to move from the ER into the Golgi are monitored by their interactions with calnexin and calreticulin (Mathieu-Rivet et al., 2020). We reasoned that the efficient secretion of proGATI by HEK-293 cells would indicate proper folding and allow usage of tools available to study vertebrate $\mathrm{N}$ - and $\mathrm{O}$-glycosylation. Affinity-purified C-ter proGATI antibodies were used to evaluate cell extracts and spent medium. Specific bands of $120 \mathrm{kDa}$ and $170 \mathrm{kDa}$ were detected in cell extracts by both $\mathrm{N}$-ter and $\mathrm{C}$-ter antibodies (Figs. 2A and S2A). A minor doublet at $\sim 37-k D a$ was also detected in cell extracts, but not in spent medium (Fig. 2A). The fact that spent medium contains a single 170-kDa protein recognized by both $\mathrm{N}$-ter and $\mathrm{C}$-ter antibodies led to its identification as HEK-proGATI; differences in the $\mathrm{N}$ - and O-linked oligosaccharides attached to proGATI produced by HEK cells and by $C$. reinhardtii would account for the difference in apparent molecular mass.

To test whether HEK-293 cells amidate proGATI, bathocuproine disulfonate (BCS) was used to deplete cellular copper, inhibiting the activity of the amidating enzyme, PAM (Bonnemaison et al., 2015). While the 170-kDa N-ter signal was unaltered following BCS treatment, the 170-kDa C-ter signal fell dramatically (Fig. 2B). To account for any differences in secretion rate, the ratio of 170-kDa C-ter signal to 170-kDa Nter signal was calculated. BCS treatment caused a four-fold reduction in this ratio, consistent with the conclusion that HEK-293 cells amidate the C-terminus of the proGATI that they secrete (Fig. 2C).

ProGATI includes six potential N-glycosylation sites (Asn-X-Ser/Thr) and several potential O-glycosylation sites (-Ser/Thr and HyP) (Fig. S1D). Digestion with either PNGase F or a mixture of O-glycosidase and neuraminidase reduced the apparent molecular mass of secreted HEK-proGATI by $\sim 15-20 \mathrm{kDa}$, consistent with the occurrence of extensive $\mathrm{N}$ - and O-glycosylation (Fig. 2D).

Successful ectosome-mediated delivery of a chemomodulatory peptide such as GATI-NH $\mathrm{NH}_{2}$ would require it to be resistant to proteolysis. Spent medium containing HEK-proGATI was used to test this hypothesis. Exposure to increasing amounts of trypsin eliminated the $\mathrm{N}$-ter signal and generated a series of smaller products recognized by the $\mathrm{C}$-ter antibody (Fig. 2E). Cleavage at the single Lys residue in the $\mathrm{N}$-ter peptide is consistent with this result (Fig. 1A). Trypsin produced a sequence of smaller products detected by the C-ter antibody. C-ter signal intensity was not diminished, with essentially complete conversion of $170 \mathrm{kDa}$ 
HEK-proGATI into a $50 \mathrm{kDa}$ and then a 37-kDa product, which may resemble the amidated $75 \mathrm{kDa}$ C-ter fragment found in mating ectosomes (Fig. 2E).

\section{Purification and domain organization of proGATI}

Since HEK-proGATI is amidated and secreted rapidly (Fig. S2B), we undertook its purification from spent medium (Fig. 3A and S2C) and analysis using mass spectrometry. Although the $\mathrm{N}$ - and O-glycans attached to HEK-proGATI will differ from those attached to proGATI produced by $C$. reinhardtii, the sites available to enzymes involved in $\mathrm{N}$ - and $\mathrm{O}$-glycosylation are expected to be the same. Purified native and deglycosylated HEK-proGATI were analyzed, using a cocktail of enzymes designed to remove both $\mathrm{N}$ - and O-linked glycans. Deglycosylation reduced its apparent molecular mass by 30 kDa (Fig. 3B).

Mass spectrometry of native HEK-proGATI identified four O-glycosylated Ser residues and two Oglycosylated HyP residues. Analysis of enzymatically deglycosylated HEK-proGATI identified five $\mathrm{N}$ glycosylation sites. The amidated C-terminus (-GATI- $\mathrm{NH}_{2}$ ) was found in both samples; $\mathrm{C}$-terminal peptides ending in -Gly and -Gly-Arg were also identified indicating that carboxypeptidase processing and amidation had not gone to completion (Fig. 3 C and D). Peptides spanning the entire sequence of HEKproGATI were identified (87.3\% coverage) (Fig. 3D).

The ability of trypsin to convert amidated HEK-proGATI into stable, amidated products as small as $37 \mathrm{kDa}$ of proGATI was generated using RoseTTAFold (Baek et al., 2021). The proGATI prediction includes three well-folded domains connected by highly extended, Pro-rich flexible linkers (Fig. 3E). The signal sequence was not included in the structural model. $\mathrm{N}$-terminal domain 1 contains 323 residues (green), terminating just before a Pro-rich region. Domain 2 includes 153 residues and domain 3 has 213 residues, ending at the $\mathrm{C}$-terminus. The 70-residue linker between domains 1 and 2 contains 37 Pro residues and a furin-like site ( $\left.\mathrm{K}^{407} \mathrm{PRK}\right)$, while 43 of the 99 residues in the second linker are Pro residues; these very Pro-rich regions likely contribute to the abnormal migration of proGATI during SDS-PAGE. Domain 3 forms an antiparallel $\beta$-sandwich and has a nominal molecular mass of $23 \mathrm{kDa}$ with a pl of 10 (Fig. 3E). This domain corresponds precisely to the C-terminal region identified by mass spectrometry of the 75-kDa amidated product in mating ectosomes, and is immediately preceded by a furin-like cleavage site. Cleavage at this site alone would release domains 1 and 2 (predicted to represent the 120-kDa N-terminal fragment), while further proteolysis at $\mathrm{K}^{407}$ might generate the 63-kDa N-terminal product. Domain 3, which includes four Cys residues, has a single predicted disulfide bond $\left(\mathrm{C}^{739}\right.$ and $\left.\mathrm{C}^{745}\right)$; although $\mathrm{C}^{742}$ and $\mathrm{C}^{817}$ are located close to each other, a significant rearrangement would be needed for disulfide bond formation. Importantly, the experimentally confirmed C-terminal amidation site, the Pro residue that is O-glycosylated $\left(\mathrm{P}^{896}\right)$ and both Asn residues that are $\mathrm{N}$-glycosylated (Asn ${ }^{814} \mathrm{ThrThr}$ and $\mathrm{Asn}{ }^{833} \mathrm{G} \operatorname{lnThr}$ ) are completely exposed and accessible for modification in the model structure (Fig. S3).

\section{Ciliary localization and mating type-specific processing of proGATI}

229 Under nutrient deprivation conditions, C. reinhardtii cells differentiate into minus and plus gametes that expresses mating type-specific genes, enabling them to recognize each other. Our previous study showed that CrPAM expression increased during gametogenesis, and that the $\mathrm{C}$-ter antigenic peptide and a longer synthetic amidated peptide (VLYPNDPAAYAAYAPGTGGGATI-NH ${ }_{2}$ ) produced a mating type-specific chemotactic response, attracting minus gametes and repelling plus gametes (Luxmi et al., 2019). These 
observations prompted investigation of proGATI in gametes. Cells, deciliated cell bodies and cilia were subjected to immunoblot analysis. Use of the $\mathrm{N}$-ter and C-ter antibodies revealed enrichment of 250-kDa proGATI in the cilia of both minus and plus gametes (Fig. 4A). In contrast, the C-ter antibody detected a 75-kDa band only in plus gametes; while detectable in plus gamete cells, the 75-kDa band was enriched in plus gamete cilia and essentially undetectable in deciliated cell bodies. Strikingly, production of amidated 75-kDa GATI is specific to plus gametes (Fig. 4A and 4B). Mass spectrometric analysis of 75-kDa GATI immunoprecipitated from plus gamete cell lysates confirmed complete amidation of its C-terminus and the presence of peptides like those identified in 75-kDa GATI immunoprecipitated from mating ectosomes

242 (Figs. 1E, F and S4).

We next used immunofluorescence microscopy to determine the subcellular localization of GATI-derived proteins in resting gametes. Maximal Z-projection confocal images of minus and plus gametes showed that the C-ter GATI signal was localized in discrete puncta throughout the cytoplasm (Fig. 4C); this signal could represent intact 250-kDa proGATI and/or the 75-kDa C-ter product derived from it. In contrast, simultaneous visualization of FMG1, a ciliary membrane glycoprotein, revealed more signal in the cilia and around the margins of the cell body. Single Z-stack images showed the accumulation of C-ter GATI signal at the cell surface, co-localized with FMG1 (Fig. 4C, inset). Diffuse C-ter GATI signal along the length of the cilia was also observed in both mating types (Fig. 4C). To confirm staining specificity, the C-ter antibody was pre-incubated with antigenic peptide; signal intensity (green) was greatly reduced in the cell body, on the cell surface and in cilia of plus gametes (Fig. 4C, lower panel). The punctate staining in the cell body could represent Golgi-derived vesicles, which may enter the ciliary membrane after accumulating on the cell surface.

\section{Mating triggers ectosomal trafficking and processing of the GATI-precursor}

Ectosome formation involves outward budding of the ciliary membrane (Wood et al., 2013). The initiation of mating triggers the formation and release of ectosomes (Cao et al., 2015); the catalytic domains of CrPAM are exposed on the outer surface of mating ectosomes and PAM is not found in the soluble secretome (Kumar et al., 2016a; Luxmi et al., 2019). ProGATI, which lacks a transmembrane domain, is in both mating ectosomes and the secretome. We utilized affinity-purified proGATI antibodies and immunogold-electron microscopy to determine its ectosomal localization.

262 Ectosomes from mating gametes were embedded in agarose and imaged by thin section transmission EM

263 (Fig. 5A); the vesicles range from $\sim 80 \mathrm{~nm}$ to $\sim 260 \mathrm{~nm}$ in diameter. Following incubation with intact 264 ectosomes, affinity-purified proGATI antibodies were visualized using a gold-tagged anti-rabbit secondary antibody and negative stain EM; signals obtained with both antibodies were localized on the ectosome surface (Fig. 5A). Ectosomes incubated only with gold-conjugated secondary antibody served as a negative 267 control.

268 Ectosomes, deciliated mixed gamete cell bodies and cilia prepared $1 \mathrm{~h}$ after the initiation of mating were 269 subject to immunoblot analysis (Fig. 5B). Based on use of both the N-ter and C-ter antibodies, cilia 270 contained only 250-kDa proGATI. In contrast, mating ectosomes contained 250-kDa proGATI along with 271 the $120 \mathrm{kDa}$-ter fragment and the $75 \mathrm{kDa}$ C-ter fragment, whereas proGATI products were not detected 272 in the cell bodies (Fig. 5B). Quantification revealed enrichment of 250-kDa proGATI in mating ectosomes 
and an even greater enrichment of both the $120 \mathrm{kDa}$ and $75 \mathrm{kDa}$ fragments (Fig. 5C), suggesting that the cleavage creating them occurs on the ectosomal surface.

For comparison, we evaluated the specificity and selectivity with which two other ciliary proteins, CrPAM and FMG1, move from cilia into ectosomes during mating (Fig. 5D and E). CrPAM was previously identified in mating ectosomes, but was not found in vegetative ectosomes (Luxmi et al., 2019), while FMG1 is present in both (Long et al., 2016; Luxmi et al., 2019). Immunoblot analysis confirmed the presence of both CrPAM and FMG1 in mating ectosomes. After an hour of mating, very little CrPAM remained in the cilia; although mating ectosomes contained CrPAM, its ectosomal levels did not exceed those in the cell body (Fig. 5D). FMG1 levels in cilia and mating ectosomes greatly exceeded those in cell bodies, but FMG1 levels in mating ectosomes did not exceed those in cilia (Fig. 5E). Thus, the cell bodies of mating gametes were essentially devoid of proGATI while both CrPAM and FMG1 were readily detected.

\section{Differential release of proGATI products from mating ectosomes}

We previously found that both CrPAM protein and enzyme activity associate with the ciliary axoneme; this interaction is disrupted by treatment with $0.6 \mathrm{M} \mathrm{NaCl}$ following detergent extraction (Kumar et al., 2016a). To explore the ciliary distribution of proGATI and its products, we isolated cilia from resting gametes of both mating types and from $1 \mathrm{~h}$ mixed gametes. Isolated cilia were first treated with Triton $\mathrm{X}$ 100 to release membrane proteins and soluble matrix components. This was followed by treatment with $0.6 \mathrm{M} \mathrm{NaCl}$ to extract proteins that were tightly bound to the axoneme; the resulting extracted axoneme pellet was solubilized in $1 \times$ SDS buffer.

The amidated 75-kDa GATI product was detected in the cilia of plus but not minus gametes (Figs. 6A and by $0.6 \mathrm{M} \mathrm{NaCl}$; it was not present in the axonemal fraction of plus gametes. The 250-kDa proGATI protein was in the detergent soluble, $0.6 \mathrm{M} \mathrm{NaCl}$ and axonemal fractions from both gametes (Figs. $6 \mathrm{~A}$ and $\mathrm{B}$ ). During gamete mating, the amidated $75-\mathrm{kDa}$ GATI product and the 250-kDa proGATI protein were released into ectosomes (Figs. 6A and B). The presence of an N-terminal fragment of proGATI in ectosomes but not in the ciliary fractions suggested that cleavage of $250 \mathrm{kDa}$ proGATI occurs on the ectosomal surface.

To evaluate how $250 \mathrm{kDa}$ proGATI (which lacks a transmembrane domain) associates with the ectosome surface, freshly isolated ectosomes were washed with $10 \mathrm{mM}$ HEPES buffer (control) or with buffer containing $10 \mathrm{mM}$ dithiothreitol (DTT) or $10 \mathrm{mM}$ EDTA, and the resulting supernatants examined for the release of GATI products, CrPAM and FMG1 (Figs. 6C and D). Neither 250-kDa proGATI, CrPAM nor FMG1 was solubilized, with signal detected only in the ectosomal pellets. In contrast, the amidated 75-kDa Cterminal product and $\mathrm{N}$-terminal 63-kDa segment were both released by washing with low ionic strength HEPES buffer; release did not occur following chelation of divalent cations with EDTA. Although not released by buffer alone or by EDTA treatment, the N-terminal 120-kDa GATI fragment was partially displaced from ectosomes by $10 \mathrm{mM}$ DTT. This effect was DTT-specific; treatment with $10 \mathrm{mM} \beta$ mercaptoethanol had no effect (Fig. S5). These results suggest that all three domains individually mediate associations with the ectosomal surface. This tripartite attachment mechanism likely explains why release of 250-kDa amidated proGATI was not observed under any conditions.

312 Distribution, processing and amidation of putative prohormone convertases in cilia 
The appearance and accumulation of the 75-kDa amidated proGATI product on plus (but not minus) gamete cilia, and of both 120- and 75-kDa proGATI products on mating ectosomes, suggested that proteolytic processing occurs on the ciliary and/or ectosomal surface or during the sorting and transit of the precursor from cilia into nascent ectosomes. Mating ectosomes contain two subtilisin-like proteases, SUB14 and VLE1; they are the closest Chlamydomonas homologs of mammalian prohormone convertases PC2 and PCSK7, respectively (Luxmi et al., 2019). To address the ciliary distribution of these putative prohormone convertases, we performed comparative proteomics of cilia from vegetative and gametic cells of both mating types. This confirmed the presence of VLE1 in vegetative cilia of both mating types (Kubo et al., 2009); SUB14 was not detectable in vegetative cilia (Fig.7A and Supplemental Data File 1). Strikingly, VLE1 was identified in the cilia of plus gametes, but was not detected in minus gamete cilia. SUB14 expression was also mating type specific, but it was present in the cilia of minus, but not plus, gametes (Fig.7A). In consequence, VLE1 is the only putative prohormone convertase present in ciliary samples that contain proteolytically processed proGATI products.

Peptides from the cytosolic, pro-, S8 and C-terminal domains of VLE1 (Fig. 7B) were identified in cilia from vegetative and plus gamete cells. In contrast, mating ectosomes and the secretome contained only peptides from the S8 and C-terminal domains (Fig. 7B). Activation of subtilisin-like prohormone convertases generally requires autoproteolytic cleavage and subsequent dissociation of the pro-domain (Shakya and Lindberg, 2020). Clustal analysis identified the-Gly-Arg-Arg site that immediately precedes the catalytic domain as the likely site for autoactivation. Autoproteolytic cleavage at this site, followed by exoproteolytic removal of the two Arg residues would produce an amidation site. Mass spectrometry revealed that all of the ciliary VLE1 had been proteolytically processed at this site and was amidated (Fig.7B); partially processed peptides derived from this region of VLE1 and ending in -Gly, -Gly-Arg or Gly-Arg-Arg were not observed. Detailed analysis of the predicted VLE1 structure (Fig. 7C) and peptides identified in cilia suggests that the pro-domain remains associated with the $\mathrm{S} 8$ domain, tethering it to the ciliary membrane even after autoproteolytic cleavage and amidation.

\section{Discussion}

339 Identification of an amidated peptide that has a mating-type specific effect on C. reinhardtii mobility led us to explore the properties of its putative precursor, the manner in which this precursor might be converted into smaller products, and the regulated secretion of its product peptides.

342 ProGATI undergoes extensive post-translational modification and contains multiple domains. The $C$.

343 reinhardtii genome encodes hundreds of proteins with the general characteristics of prepropeptides 344 (Luxmi et al., 2019). As observed in the ER of metazoans, preproGATI undergoes signal peptide removal, along with the first steps of $\mathrm{N}$ - and O-glycosylation (Fig. 8A). ProGATI, like many other putative $C$. reinhardtii propeptides, is quite large, with a predicted molecular mass of $90.6 \mathrm{kDa}$, and multiple domains connected by Pro-rich linker regions. In addition to the Asn and Ser/Thr sites subject to N- and Oglycosylation in metazoan propeptides, hydroxy-Pro residues in domains 1 and 3 of proGATI are Oglycosylated (Fig. 3). In plants and algae, hydroxy-Pro residues are major O-glycosylation sites for addition of pentose (arabinogalactan) sugars (Bollig et al., 2007; Tan et al., 2003). With a unique core structure to

351 their $\mathrm{N}$-glycans and unique O-glycosyl transferases, propeptides synthesized by $\mathrm{C}$. reinhardtii differ in 
important ways from metazoan propeptides (Joshi et al., 2018; Mathieu-Rivet et al., 2020; Schulze et al., 2017; Xu et al., 2020).

With the endoproteolytic cleavage of proGATI limited to the surface of mating ectosomes (Fig. 5), we considered the possibility that its structural domains might play a role in its localization. Despite sharing little sequence similarity, a DALI search (Holm, 2020) revealed structural relatives for each proGATI domain: domain 1 is distantly similar to halohydrin dehalogenase from llumobacter coccineus (z score = 6.2, RMSD = $13.6 \AA$; $619 \mathrm{~W}$ ); domain 2 is related to EPR3 (a carbohydrate receptor) from Lotus japonicus ( $\mathrm{z}$ score $=4.2, \mathrm{RMSD}=2.4 \AA$; $6 \mathrm{QUP}$ ); and domain 3 resembles a chitosanase from Paenibacillus sp. (z score $=9.3, \mathrm{RMSD}=2.5 \AA ; 4 \mathrm{ZXE})$. The ability of EPR3 and chitosanase to interact with carbohydrates (Kawaharada et al., 2015; Lopez-Moya et al., 2019; Wong et al., 2020) suggests that domains 2 and 3 might play a role in the tripartite interaction of proGATI with the ectosomal surface, with subsequent endoproteolytic cleavages facilitating release of specific fragments.

For signaling peptides released on ectosomes, protease resistance may be especially important. Domain 3 corresponds precisely to the 75-kDa C-ter fragment (Fig. 3E). N-glycosylation of the two potential sites in domain 3, along with O-glycosylation of a hydroxy-Pro located nine residues from the amidated Cterminus likely accounts for the $\sim 50 \mathrm{kDa}$ discrepancy between its apparent molecular mass and the mass of its polypeptide chain ( $23 \mathrm{kDa}$ ) (Figs 3 and $8 \mathrm{~A}$ ). The endoproteolytic cleavage that produces $75-\mathrm{kDa} \mathrm{C}$ ter fragment in ectosomes would also produce the 120-kDa N-ter fragment. Although the C-terminus of proGATI is accessible to PAM, converting its C-terminus from -GATI-Gly to -GATI- $\mathrm{NH}_{2}$, the amidated Cterminus is trypsin resistant (Fig. 2) and stable when exposed on the ciliary membrane and the surface of

372 mating ectosomes.

373 Examination of the first $C$. reinhardtii protein known to serve as a peptide precursor indicates that it shares 374 many similarities with vertebrate peptide precursors. However, its larger size, more complex domain 375 organization and extensive modifications suggest that this precursor carries additional information 376 needed to ensure that its signaling task can be accomplished.

377 Controlling the endoproteolytic cleavage of proGATI. ProGATI cleavage is linked to both mating type and subcellular location (Fig. 8B). The cell bodies of plus and minus gametes contain intact proGATI, but the 75-kDa C-ter fragment is found only in the cilia of plus gametes. Both $\mathrm{N}$ - and C-ter proGATI fragments accumulate in mating ectosomes. In metazoans, the cell type-specific cleavage of propeptides such as proopiomelanocortin (Kumar et al., 2016b) and proglucagon (Drucker, 2018) reflects the cell type-specific expression of subtilisin-like prohormone convertases. Mating ectosomes contain only two subtilisin-like proteases, VLE1 and SUB14 (Luxmi et al., 2018). The presence of VLE1, but not SUB14, in the cilia of plus gametes, where proGATI cleavage occurs, suggests that VLE1 serves as a proGATI convertase. VLE1 is also localized to the ciliary membrane in vegetative cells (Kubo et al., 2009; Wood et al., 2013); its release into vegetative ectosomes provides access to the mother cell wall, which it degrades, allowing release of mitotic progeny. A matrix metalloproteinase (gametolysin), not VLE1, cleaves the gametic cell wall prior

388 to fusion (Kinoshita et al., 1992), suggesting that VLE1 has additional targets on plus gamete cilia and/or 389 in the extracellular milieu. VLE1 cleaves to the C-terminal side of basic residues, although the required sequence context is poorly understood (Matsuda et al., 1995). Endoproteolytic cleavage of proGATI after 
a basic residue within a furin-like cleavage site $\left(R^{693} F S R \downarrow\right)$ produces the amidated $75 \mathrm{kDa}$ C-ter fragment (Figs. $1 \mathrm{~F}$ and $8 \mathrm{~A}$ ).

In metazoans, luminal $\mathrm{pH}$ plays a central role in controlling prohormone convertase activation and the storage of product peptides in secretory granules (Halban, 1991). With proGATI cleavage products accumulating on the surface of mating ectosomes, luminal $\mathrm{pH}$ cannot serve as a regulatory factor. The pro-domains of subtilisin-like endoproteases facilitate catalytic domain folding and inhibit activity. Protease activation requires autoproteolytic cleavage, separating the pro-domain from the catalytic domain (Shakya and Lindberg, 2020). Additional cleavages within the pro-domain may also be required for pro-domain release and S8 domain activation. Consistent with this, active VLE1 purified from culture medium following hatching lacked its pro-domain (Kubo et al., 2009). Our analysis of the soluble mating secretome identified the intact VLE1 S8/C-terminal domain, but not the N-terminal/pro-domain (Fig. 8B).

Sequence analysis revealed an unusual pro-domain in VLE1, with homologous sequences found only in other members of the volvocine algae (e.g. the protease VheA, required for release of juvenile Volvox from the parental spheroid (Fukada et al., 2006)). To understand how VLE1 activation might occur, a structural model was built using RoseTTAFold (Baek et al., 2021) (Figs. 7C and S6). The active site contains a classic Ser-His-Asp catalytic triad and an Asn residue that stabilizes the transition state in the oxyanion hole (Fig. 7C) (Shakya and Lindberg, 2020). The VLE1 pro-domain consists of an $\alpha / \beta$ fold that makes extensive contact with one face of the S8 domain. Emanating from this $\alpha / \beta$ region is an extended strand that arches over the active site, occluding it; the -Gly-Arg-Arg cleavage/amidation site is exposed on the surface. Given the large surface area buried by the pro-domain, cleavage at the -Gly-Arg-Arg site seems unlikely to result in pro-domain release from the catalytic core.

412 For amidation to occur, the extended strand must swing away from the catalytic site, enabling carboxypeptidases to remove remaining Arg residue(s) and allowing PAM to access the exposed Gly residue. The functional consequences of amidation at this site remain to be determined. Binding of the amidated pro-domain $\mathrm{C}$-terminus to a target protein might facilitate retention of the $\mathrm{N}$-terminal/prodomain of this type II membrane protein in the ciliary membrane, allowing the enzymatically active S8/Cterminal domain to enter mating ectosomes.

Ciliary ectosomes as an ancient mode of rapid, regulated secretion. Changes in protein expression allow unicellular organisms like $C$. reinhardtii to regulate secretion of the enzymes needed to acquire specific nutrients, but this type of response requires time. In metazoans, peptides stored in secretory granules can be released within milliseconds of signal receipt. Our data indicate that ciliary ectosomes serve as an ancient mode of rapid, regulated secretion. Like the assembly of secretory granules, the assembly of ciliary ectosomes is a highly regulated process. The cilia of both vegetative cells and mating gametes release bioactive ectosomes; their compositions are unique and developmentally regulated (Wood et al., 2013; Long et al., 2016; Cao et al., 2015; Luxmi et al., 2019). Since ectosomes are formed from the ciliary membrane, proteins targeted to ectosomes must first gain access to the cilium. The transition zone plays an essential role in establishing and maintaining the unique lipid and protein composition of the ciliary membrane (Long and Huang, 2020; Nachury and Mick, 2019; Takao and Verhey, 2016). 
ectosomes but not in vegetative ectosomes (Luxmi et al., 2019); cleavage of CrPAM does not occur and active enzyme does not appear in the soluble secretome. While VLE1 is found in the cilia of plus gametes, the presence of the $\mathrm{N}$-terminal/pro-domains, along with the intact S8/C-terminal domains suggests that ciliary VLE1 is not active. VLE1 recovered from mating ectosomes and the secretome lacks the Nterminal/pro-domains, indicating that it has been activated. While proGATI is present in the cilia of plus and minus gametes, cleavage occurs only in the cilia of plus gametes; more extensive cleavage of proGATI is linked to its release in mating ectosomes, where both $\mathrm{N}$-ter and $\mathrm{C}$-ter fragments accumulate. Although metazoan secretory granules generally store mature product peptides, the cleavage of proatrial natriuretic factor by corin, a type II plasma membrane enzyme like VLE1, is tied to the exocytosis of atrial granules (Glembotski et al., 1988).

441 Metazoan peptide-containing secretory granules can be stored for long periods of time, with release 442 responding rapidly to receptor-mediated secretagogue stimulation. In C. reinhardtii, ciliary adhesion of mating gametes causes ectosomes to appear on the ciliary surface in a process that requires receptormediated signaling; strikingly, activating gametes directly with dibutyryl-cAMP does not lead to ectosome release (Cao et al., 2015). The signals that control food intake in mammals require localization of the melanocortin-4 receptor to the primary cilia of hypothalamic neurons (Wang et al., 2021). The ciliary localization of free fatty acid receptor- 4 and prostaglandin-E receptor- 4 in $\alpha$ - and $\beta$-cells plays an essential role in hormone secretion (Wu et al., 2021) and mice lacking primary cilia on their $\beta$-cells exhibit impaired glucose homeostasis and develop diabetes (Hughes et al., 2020).

As observed in mammals, multiple receptors have been identified in C. reinhardtii cilia (Huang et al., 2004; Luxmi et al., 2019; Ranjan et al., 2019). By taking advantage of the ease with which cilia can be isolated from $C$. reinhardtii, its precisely delineated sexual reproductive cycle and the identification of a bioactive amidated peptide in mating ectosomes, it is now clear that cilia provide a means of controlling 454 endoproteolytic processing of propeptides and the release of mature bioactive peptide products.

455 Although, the stimulus-dependent secretion of neuropeptides from dense core vesicles stored at the 456 presynaptic endings of axons or exported to dendrites has been well studied (Ding et al., 2019), whether 457 bioactive peptides are released from the primary cilia of neurons and endocrine cells remains to be 458 determined.

459 In summary, this study provides a mechanism through which amidated peptide products are synthesized, 460 post-translationally modified, trafficked into cilia and released into ciliary ectosomes by a unicellular 461 organism, C. reinhardtii. As both cilia and the peptidergic signaling machinery are conserved throughout 462 eukaryotes, this study should shed light on the mechanisms through which cilia-based secretion is 463 regulated in health and dysregulated in various ciliopathies. 


\section{Key Resource Table}

\begin{tabular}{|c|c|c|}
\hline Reagent or Resource & Source & Identifier \\
\hline \multicolumn{3}{|l|}{ Antibodies } \\
\hline CrPAM luminal (rabbit) & (Kumar, 2017) & CrPHM-PAL-rhod \\
\hline CrFMG1 (mouse) & Dr. R. Bloodgood & (Bloodgood et al., 1986) \\
\hline ProGATI N-ter (rabbit) & This study & CT237(N-ter) \\
\hline ProGATI C-ter (rabbit) & This study & CT237(C-ter) \\
\hline \multicolumn{3}{|c|}{ Chemicals, Peptides, Reagent Kits } \\
\hline Amidated peptide, GATI-NH ${ }_{2}$ & Biomatik & (Luxmi et al., 2019) \\
\hline Control peptide, GATI-OH & Biomatik & (Luxmi et al., 2019) \\
\hline $\begin{array}{l}\text { Glycine-extended peptide, } \\
\text { GATI-Gly }\end{array}$ & Biomatik & (Luxmi et al., 2019) \\
\hline $\begin{array}{l}\text { N-ter peptide } \\
\text { (CYELGLDIDGKPAHPAAT-NH }{ }_{2} \text { ) }\end{array}$ & Biomatik & This study \\
\hline \multicolumn{3}{|l|}{ Experimental model } \\
\hline $\begin{array}{l}\text { Chlamydomonas reinhardtii } \\
\text { strains }\end{array}$ & $\begin{array}{l}\text { Chlamydomonas } \\
\text { resource center }\end{array}$ & CC124 and CC125 \\
\hline HEK-293 cells & $\begin{array}{l}\text { American Type Culture } \\
\text { Collection }\end{array}$ & CRL-1573 \\
\hline \multicolumn{3}{|l|}{ Software } \\
\hline Image J & $\mathrm{NIH}$ & https://imagej.nih.gov/ij/ \\
\hline UNICORN FPLC software & GE Healthcare & ver. 5.2 \\
\hline Prism 5 & GraphPad & https://www.graphpad.com \\
\hline PyMOL & Schrödinger LLC & ver. 2.4.0 https://pymol.org \\
\hline RoseTTAFold & Baker laboratory & https://robetta.bakerlab.org/ \\
\hline DALI & Holm Group & https://ekhidna2.biocenter.helsinki.fi/dali/ \\
\hline
\end{tabular}

\section{Methods}

468 Chlamydomonas cell culture and gametogenesis induction

Wild type $C$. reinhardtii mating type minus (CC124) and plus (CC125) strains were cultured in R-medium (Harris, 2009) aerated with $95 \%$ air and $5 \% \mathrm{CO}_{2}$ under a $12 \mathrm{~h}$ light $/ 12 \mathrm{~h}$ dark cycle at $22{ }^{\circ} \mathrm{C}$. The strains were obtained from the Chlamydomonas Resource Center (https://www.chlamycollection.org/). To induce 
gametogenesis, vegetative cells of both mating types were washed, and resuspended in nitrogen-deficient minimal medium (M-N medium) for 24-36 h under aeration and a $12 \mathrm{~h}$ light/12 $\mathrm{h}$ dark cycle.

474 Preparation of ectosomes, cilia and cell lysates from mating gametes

475 Gametes of both mating types were resuspended in $10 \mathrm{ml}$ of fresh nitrogen-free $\mathrm{M}-\mathrm{N}$ medium at a density of $5 \times 10^{6}$ cells $/ \mathrm{ml}$. An equal number of mating type minus and plus gametes were mixed for $1 \mathrm{~h}$; after incubation, ectosomes were isolated by differential centrifugation as described previously (Luxmi et al., 2019). Ectosome-enriched pellets were resuspended in TMT buffer [ $20 \mathrm{mM}$ 2-[tris(hydroxymethyl)methylamino]-ethanesulfonic acid (TES), pH 7.4, $10 \mathrm{mM}$ mannitol, 1\% Triton X-100] containing a protease inhibitor cocktail (cOmplete ULTRA Tablets, \# 05892791001, Roche, Basel, Switzerland) and $0.3 \mathrm{mg} / \mathrm{ml}$ phenylmethylsulfonyl fluoride (PMSF, Sigma Chemical Co., St. Louis, MO). For electron microscopy (see below), ectosome-rich pellets were resuspended in $10 \mathrm{mM}$ HEPES buffer containing the same protease inhibitors.

Cell lysates were prepared as described previously (Luxmi et al., 2019). Minus and plus mixed gametic cells were harvested by centrifugation at 1,600 xg and resuspended in TMT buffer containing $0.2 \mathrm{M} \mathrm{NaCl}$, the protease inhibitor cocktail and $0.3 \mathrm{mg} / \mathrm{ml} \mathrm{PMSF}$. Gametes were deciliated using dibucaine and cilia isolated by standard methods and resuspended in HMS buffer (10 mM HEPES, pH7.4, $5 \mathrm{mM} \mathrm{MgSO}_{4}$ and $4 \%$ sucrose) (King, 1995; Witman, 1986); the deciliated cell bodies were resuspended in TMT buffer containing $0.2 \mathrm{M}$ $\mathrm{NaCl}$, protease inhibitor cocktail and $0.3 \mathrm{mg} / \mathrm{ml}$ PMSF. Protein content was determined using the bicinchoninic acid assay (BCA) (Thermo Fisher Scientific, Rockford, IL, USA).

491 Samples for electrophoresis were prepared by mixing with $2 \times$ Laemmli sample buffer (Bio-rad, Hercules, 492 California) and denatured at $55^{\circ} \mathrm{C}$ for $5 \mathrm{~min}$; samples were fractionated in Criterion TGX 4-15\% SDS-PAGE gradient gels (Bio-rad) and transferred to PVDF membranes. Proteins were visualized using Coomassie brilliant blue, the blots destained and then blocked using 5\% milk dissolved in 1\% Tween-20 in Tris-buffered saline. Incubation with primary antibodies was carried out overnight at $4^{\circ} \mathrm{C}$; after washing, horseradish peroxidase-tagged second antibody (Thermo Fisher Scientific) was applied for $1 \mathrm{~h}$ at room temperature and the signal visualized using SuperSignal enhanced chemiluminescent (ECL) reagent (Thermo Fisher Scientific, \#34080).

\section{Ciliary fractionation}

500 Isolated cilia were incubated with TMT buffer for $60 \mathrm{~min}$ at $4^{\circ} \mathrm{C}$, to solubilize ciliary membrane and matrix 501 proteins. The remaining axonemes were incubated with $0.6 \mathrm{M} \mathrm{NaCl}$ in $\mathrm{TM}$ buffer to release axonemal 502 proteins tightly bound via ionic interactions. The extracted axonemal pellet was dissolved in SDS lysis buffer $503(0.5 \%(\mathrm{w} / \mathrm{v})$ sodium dodecyl sulfate, $0.05 \mathrm{M}$ Tris. $\mathrm{Cl}, \mathrm{pH} 8.0)$ containing protease inhibitor cocktail and 0.3 $504 \mathrm{mg} / \mathrm{ml} \mathrm{PMSF}$. Soluble samples were desalted and concentrated using Amicon concentrators (10-kDa cut-

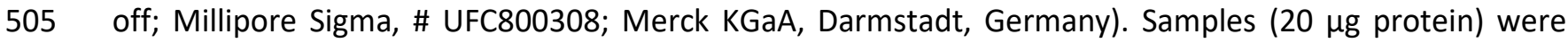
506 fractionated by SDS-PAGE and analyzed by immunoblotting.

\section{Immunofluorescence microscopy}

508 Resting gametes were harvested by centrifugation at 1,600 $\times \mathrm{g}$ and fixed with $2 \%$ paraformaldehyde in 509 buffer containing $30 \mathrm{mM}$ HEPES, $5 \mathrm{mM} \mathrm{EGTA}, 5 \mathrm{mM} \mathrm{MgSO}_{4}, 25 \mathrm{mM} \mathrm{KCl}, 4 \%$ sucrose, pH 7.0. Cells were 510 allowed to adhere to $0.1 \%$ polyethyleneimine-coated coverslips for $10 \mathrm{~min}$ and then treated with methanol 
511 for $10 \mathrm{~min}$ at $-20^{\circ} \mathrm{C}$. Subsequent blocking and antibody incubation were done as described (Luxmi et al., 512 2019). Primary antibodies used were affinity-purified rabbit N-ter and C-ter proGATI antibodies (from 513 CT327; 1:500) and mouse FMG1 (1:1000). Alexa 488 anti-rabbit (Life Technologies, Thermo Fisher 514 Scientific) (1:500) and Cy3 anti-mouse (Jackson ImmunoResearch Laboratories, West Grove, PA) (1:2000) 515 conjugates were used as secondary antibodies. Images were obtained using a Zeiss 880 confocal 516 microscope with a $63 \times$ oil objective.

517 Electron microscopy analysis

518 Immuno-gold labeling of ectosomes was performed as described previously (Luxmi et al., 2019) with the 519 following modifications. Freshly isolated mating ectosomes were fixed with $1 \%$ paraformaldehyde (EM 520 grade) and incubated on ice for $30 \mathrm{~min}$. Fixed samples were placed on glow-discharged 400-mesh carbon521 coated nickel grids (Electron Microscopy Sciences, Hatfield, PA) for 10-20 min and then washed with 1x PBS $522(137 \mathrm{mM} \mathrm{NaCl}, 10 \mathrm{mM}$ phosphate, $2.7 \mathrm{mM} \mathrm{KCl} \mathrm{pH} \mathrm{7.4)} \mathrm{and} \mathrm{incubated} \mathrm{with} 50 \mathrm{mM}$ glycine. Samples were 523 incubated overnight at $4^{\circ} \mathrm{C}$ with affinity-purified $\mathrm{N}$-ter and $\mathrm{C}$-ter antibodies (1:10), washed and incubated 524 for $1 \mathrm{~h}$ at room temperature with gold conjugated (10-nm) goat anti-rabbit-lgG (1:15, Electron Microscopy 525 Sciences).

526 For thin section EM, freshly isolated ectosomes were fixed with $2.5 \%$ glutaraldehyde in $0.1 \mathrm{M}$ cacodylate 527 buffer, $\mathrm{pH} 7.4$ for $1 \mathrm{~h}$ at $4^{\circ} \mathrm{C}$. After fixation, ectosomes were centrifuged at $424,000 \mathrm{xg}$ for $30 \mathrm{~min}$ and the 528 ectosome pellet was washed with $0.1 \mathrm{M}$ cacodylate buffer, $\mathrm{pH}$ 7.4. Pellets were then transferred to $0.5 \mathrm{ml}$ 529 tubes; after the buffer was carefully removed, ultra-low gelling agarose (100 $\mu$ of $4 \%$ ) was added and the 530 sample was immediately centrifuged at 1,600 $\mathrm{xg}$ for $10 \mathrm{~min}$ at room temperature. Tubes were then placed 531 on ice for $10 \mathrm{~min}$ to solidify the agarose. Ultra-thin sections of agarose-embedded ectosomes were 532 mounted on 200-mesh copper/rhodium grids, and imaged using a H-7650 transmission EM (Hitachi High 533 Technologies Corporation, Tokyo, Japan) operating at $80 \mathrm{kV}$.

534 PreproGATI in HEK-293 cells

535 HEK-293 cells were maintained in DMEM/F12 medium containing 10\% fetal calf serum (Hyclone), 100 536 units $/ \mathrm{ml}$ penicillin-streptomycin and $25 \mathrm{mM} \mathrm{HEPES}, \mathrm{pH} 7.4$ at $37^{\circ} \mathrm{C}$ in a $5 \% \mathrm{CO}_{2}$ incubator. A cDNA (2742 537 bp) encoding preproGATI was synthesized and cloned into pUC57 (GenScript). This cDNA was then 538 subcloned into $\mathrm{pCl}$-neo (Promega, Madison, $\mathrm{WI}$ ) and verified by sequencing. Transient transfections were 539 performed using lipofectamine 3000 (Invitrogen, Thermo Fisher Scientific) and stable populations of HEK540293 cells expressing preproGATI were generated by selecting cells in DMEM/F12 medium containing 0.5 $541 \mathrm{mg} / \mathrm{ml} \mathrm{G} 418$ disulfate (KSE Scientific, Durham, NC). For analyzing spent medium, cells were washed with 542 serum-free medium [DMEM/F-12 medium containing insulin-transferrin-selenium (ITS) (Thermo Fisher 543 Scientific), $25 \mathrm{mM} \mathrm{HEPES,} \mathrm{pH} \mathrm{7.4,} 100$ units/ml penicillin-streptomycin, $1 \mathrm{mg} / \mathrm{ml} \mathrm{BSA}$ ] and then incubated 544 in serum-free medium at $37^{\circ} \mathrm{C}$ with $5 \% \mathrm{CO}_{2}$. Cell lysates were prepared in $1 x$ SDS lysis buffer with $1 \mathrm{x}$ 545 protease inhibitor cocktail (Sigma, \# P8340) and $0.3 \mathrm{mg} / \mathrm{ml} \mathrm{PMSF}$. Soluble fractions (equal protein) were 546 analyzed using standard electrophoretic and immunoblotting techniques.

547 HEK-proGATI purification

548 Stably transfected HEK-293 cells expressing preproGATI (HEK-GATI cells) were washed and cultured in 549 serum-free media lacking ITS and BSA for 16-18 h. Spent medium was collected and centrifuged at 100 xg 
to remove cell debris. Protease inhibitor cocktail and $0.3 \mathrm{mg} / \mathrm{ml} \mathrm{PMSF}$ were added to the medium, which was stored at $-80^{\circ} \mathrm{C}$. Spent medium pooled from multiple sequential collections was used for purification. A weak anion exchange column, HiTrap ANX Sepharose FF (Cytiva \# 17-5163-01; Sigma), was used to concentrate the HEK-proGATI ( $\mathrm{pl}=6.04$ ). Prior to sample loading, the $\mathrm{pH}$ of the spent medium was adjusted to 7.5 and the sample centrifuged at $10,000 \mathrm{xg}$ for $15 \mathrm{~min}$ to remove any insoluble material. The HiTrap ANX Sepharose FF column was washed with water, and equilibrated with $20 \mathrm{mM}$ Tris, pH 7.5 containing $100 \mathrm{mM} \mathrm{NaCl}$ and 5\% glycerol. The sample was loaded with a peristaltic pump and the flowthrough discarded. The column was washed with $20 \mathrm{mM}$ Tris, pH 7.5 buffer containing $100 \mathrm{mM} \mathrm{NaCl}$ and $5 \%$ Glycerol until the phenol red from the spent medium was no longer visible. Proteins were then eluted using an AKTA Purifier 10 FPLC System (GE Healthcare, Fairfield, CT), with a gradient of $100 \mathrm{mM}$ to $1 \mathrm{M}$ $\mathrm{NaCl}$ in $20 \mathrm{mM}$ Tris buffer containing $5 \%$ glycerol, a flow rate of $1 \mathrm{ml} / \mathrm{min}$ and a total elution volume of 40 $\mathrm{ml}$. The collected fractions were analyzed using 4-15\% SDS-PAGE gels, immunoblotted and probed with the C-ter antibody. Peak fractions were pooled and further purified by gel filtration using a Superdex 200 Increase 10/300 GL (GE Healthcare, 28-9909-44) column equilibrated with 20 mM HEPES, pH 7.4 containing $0.5 \mathrm{M} \mathrm{NaCl}$ (Fig. S2C). Fractions were pooled based on SDS-PAGE analysis; purified HEK-proGATI $(\sim 5 \mu \mathrm{g})$ was then analyzed by mass spectrometry (see below). Approximately $5 \mathrm{mg}$ of HEK-proGATI was purified from $500 \mathrm{ml}$ of spent medium.

\section{BCS treatment of HEK-GATI cells}

HEK-GATI cells plated into 24 well dishes were washed and incubated for $30 \mathrm{~min}$ in serum-free media, at $37^{\circ} \mathrm{C}$ with $5 \% \mathrm{CO}_{2}$. Cells were then treated with serum-free media containing $50 \mu \mathrm{M}$ bathocuproine disulfonic acid (BCS, Sigma) as described by (Bonnemaison et al., 2015). Cells treated with medium only were used as control. Spent medium was collected and centrifuged at $100 \mathrm{xg}$ to remove cell debris. Cell lysates (15 $\mu \mathrm{g}, \sim 20 \%$ of total) and spent media (15 $\mu \mathrm{l}, 5 \%$ of total) were fractionated in $4-15 \%$ SDS-PAGE gels and analyzed by immunoblotting.

\section{Antibody generation}

Synthetic peptides (BioMatik, Kitchener, Ontario, Canada) from the N-terminal (YELGLDIDGKPAHPAAT-NH 2 , $1.5 \mathrm{mg}$ ) and C-terminal (YAPGTGGGATI-NH $2,1.5 \mathrm{mg}$ ) regions of proGATI were individually conjugated to keyhole limpet hemocyanin (KLH; 3 mg; Sigma H-7017, Lot 110K4833). An additional Cys residue added to the $\mathrm{N}$-ter peptide allowed conjugation to $\mathrm{KLH}$ using $\mathrm{m}$-maleimidobenzoyl-N-hydroxysuccinimide ester. $\mathrm{KLH}$ conjugation of the C-ter peptide used glutaraldehyde, facilitating the generation of amide specific antibodies. Three rabbits (CT327, СT330, and CT332) were immunized with a mixture of KLH-conjugated $\mathrm{N}$-ter and C-ter peptides by Covance Immunology Services (Denver, PA). Crude IgG was obtained by ammonium sulfate precipitation from the sera of immunized rabbits and $\mathrm{N}$-ter and $\mathrm{C}$-ter antibodies further purified by peptide affinity chromatography. The N-ter (pl 5.5) and C-ter ( $\mathrm{pl}$ 9.9) peptides were conjugated to Affi-Gel-10 (Bio-rad) agarose beads for affinity-purification. Recoveries during affinity purification and cross-reactivity of purified antibodies were examined using solid phase assays. High-affinity binding 96well plates coated with $\mathrm{N}$-ter $(5 \mathrm{ng})$ or $\mathrm{C}$-ter $(5 \mathrm{ng})$ peptide were prepared and serial 3-fold dilutions of each sample were tested.

\section{Deglycosylation assays}


The presence of $\mathrm{N}$-linked oligosaccharides was examined using PNGase $\mathrm{F}$ (New England Biolabs (NEB), Ipswich, MA, \# P0708S) and the presence of O-linked sugars was assessed by combined treatment with Oglycosidase (NEB \#P0733S) and $\alpha 2-3,6,8$ neuraminidase (NEB \#P0720S). Mating C. reinhardtii ectosomes $(20 \mu \mathrm{g})$ and spent medium $(9 \mu \mathrm{l})$ from HEK-293 cells expressing proGATI were denatured by heating at $100^{\circ} \mathrm{C}$ for $10 \mathrm{~min}$ with $1 \mathrm{x}$ denaturing buffer. Following denaturation, samples were deglycosylated following the manufacturer's protocol. Samples incubated on ice only (-) and treated with buffer only (+B) were used as controls. For mass spectrometry analysis (see below), purified HEK-proGATI ( $\sim \mu \mathrm{g}$ ) was denatured and deglycosylated using deglycosylation mix II (NEB, \#P6044S), which contains the enzymes needed to remove $\mathrm{N}$-linked and many common O-linked glycans. The deglycosylated sample was buffer exchanged using Zeba ${ }^{\mathrm{TM}}$ spin desalting columns (40K Mol. Wt. cutoff; Thermo Fisher Scientific, \#87768).

\section{Immunoprecipitation}

600 Immunoprecipitation was performed using with slight modifications of previous protocols (Miller et al., 2017). Cross-reactive proteins were immunoprecipitated from plus gametic cell lysates and from mating ectosomes using affinity-purified C-ter antibody. Before immunoprecipitation, samples were denatured. An equal volume of $1 \times$ SDS-P buffer ( $50 \mathrm{mM}$ Tris pH 7.6, 1\% SDS, $130 \mathrm{mM} \mathrm{NaCl}, 5 \mathrm{mM}$ EDTA, $50 \mathrm{mM} \mathrm{NaF}$, $10 \mathrm{mM} \mathrm{NaPP}$ ) containing $0.3 \mathrm{mg} / \mathrm{ml} \mathrm{PMSF}$, protease inhibitor cocktail and PhosStop (Roche) was added to the TMT cell lysate (1 $\mathrm{mg}$ protein) or mating ectosomes (1 $\mathrm{mg}$ protein) and samples were heated at $55^{\circ} \mathrm{C}$ for $5 \mathrm{~min}$. Samples were allowed to cool and incubated with 0.5 volume (for cell lysate) or 1.0 volume (for ectosomes) of 15\% NP-40 for 20 min on ice. Samples were then diluted with 5 volumes of TESmannitol (TM) buffer containing protease inhibitor cocktail, $0.3 \mathrm{mg} / \mathrm{ml}$ PMSF and PhosStop. Each sample was centrifuged at $15,000 \mathrm{xg}$ for $15 \mathrm{~min}$ at $4^{\circ} \mathrm{C}$ to remove any insoluble material. For pre-clearing, washed Protein A agarose beads ( $50 \mu \mathrm{l}$ ) (Thermo Fisher Scientific, \#22810) were added, samples were tumbled for $30 \mathrm{~min}$ at $4^{\circ} \mathrm{C}$ and then centrifuged at $100 \mathrm{xg}$ for $3 \mathrm{~min}$. Affinity-purified C-terminal antibody (100 $\left.\mu \mathrm{l}\right)$ was then added to the pre-cleared supernatants, followed by Protein A beads $(50 \mu l)$ that had been washed with 1x TMT buffer containing 1x protease inhibitor cocktail, $0.3 \mathrm{mg} / \mathrm{ml}$ PMSF and 1x Phos Stop. After overnight incubation at $4^{\circ} \mathrm{C}$, beads were pelleted and the unbound fraction saved; beads were then washed once with TMT buffer containing $0.5 \mathrm{M} \mathrm{NaCl}$ and twice with TM buffer containing protease inhibitor cocktail, $0.3 \mathrm{mg} / \mathrm{ml}$ PMSF and Phos Stop. Bound protein was eluted by boiling in $2 x$ Laemmli sample buffer (Bio-rad) and particulate material removed by centrifugation at $15,000 \mathrm{xg}$ at room temperature. The input (15 $\mu \mathrm{g}$ ) and eluted proteins ( $2 \%$ of IPT) were fractionated in $4-15 \%$ SDS-PAGE gels (Bio-rad) and analyzed by immunoblotting. For mass spectrometry, samples were fractionated by SDS-PAGE and visualized using QC colloidal Coomassie stain (Bio-rad); the 75-kDa band was excised from the plus gamete cell lysate and mating ectosome samples.

\section{Mass spectrometry}

623 Excised gel bands were destained using $40 \%$ ethanol and $10 \%$ acetic acid in water, equilibrated to pH 8 in $624100 \mathrm{mM}$ ammonium bicarbonate, reduced by incubation with $10 \mathrm{mM}$ dithiothreitol in $100 \mathrm{mM}$ ammonium 625 bicarbonate $\left(1 \mathrm{hr}\right.$ at $\left.37^{\circ} \mathrm{C}\right)$ and alkylated by incubation with $55 \mathrm{mM}$ iodoacetamide in $100 \mathrm{mM}$ ammonium 626 bicarbonate ( $45 \mathrm{~min}$ at $37^{\circ} \mathrm{C}$ in the dark). Gel bands were dehydrated using acetonitrile, dried, and then 627 rehydrated in a $12.5 \mathrm{ng} / \mu \mathrm{L}$ trypsin solution (Promega porcine sequencing grade trypsin) in $100 \mathrm{mM}$ 628 ammonium bicarbonate. Proteolysis proceeded for $16 \mathrm{hr}$ at $37^{\circ} \mathrm{C}$. Tryptic peptides were extracted using 
alternating washes with $100 \mathrm{mM}$ ammonium bicarbonate and $5 \%$ formic acid in $50 \%$ acetonitrile and a final wash cycle with $100 \mathrm{mM}$ ammonium bicarbonate and $100 \%$ acetonitrile. Peptide solutions were pooled, dried and peptides resuspended in $0.1 \%$ formic acid in water prior to mass spectrometry analysis. Purified HEK-proGATI was diluted with $100 \mathrm{mM}$ ammonium bicarbonate in water and subjected to reduction and alkylation using $5 \mathrm{mM}$ dithiothreitol in $100 \mathrm{mM}$ ammonium bicarbonate $\left(1.5 \mathrm{hr}\right.$ at $\left.37^{\circ} \mathrm{C}\right)$ and $10 \mathrm{mM}$ iodoacetamide in $100 \mathrm{mM}$ ammonium bicarbonate ( $45 \mathrm{~min}$ at $37^{\circ} \mathrm{C}$ in the dark), respectively. Promega sequencing grade trypsin was added (1:20 w/w, enzyme:protein) and proteolysis proceeded for $16 \mathrm{hr}$ at $37^{\circ} \mathrm{C}$. Digestion was quenched by addition of concentrated formic acid. Peptides were desalted using high capacity $\mathrm{C}_{18}$ desalting spin columns (Pierce \#89851; ThermoFisher). Desalted peptides were dried to completion and resuspended in $0.1 \%$ formic acid in water prior to mass spectrometry analysis.

Resuspended peptides were analyzed using nanoflow ultra-high performance liquid chromatography (UPLC) coupled to tandem mass spectrometry (MS/MS) using a Dionex Ultimate 3000 RSLCnano UPLC system and Q Exactive HF mass spectrometer (ThermoFisher Scientific). Peptides were loaded onto a 75 $\mu \mathrm{m} \times 25 \mathrm{~cm}$ nanoEase m/z Peptide BEH $C_{18}$ analytical column (Waters Corporation, Milford, MA), separated using either a 1 or $2 \mathrm{hr}$ reversed-phase UPLC gradient, and directly ionized into the Q Exactive HF using positive mode electrospray ionization. MS/MS data were acquired using a data-dependent Top15 acquisition method. All raw data were searched against the $C$. reinhardtii proteome using the following variable modifications: Modification set 1 - Met and Pro oxidation, Ser, Thr, and Tyr phosphorylation, Glu, Asp, peptide C-term amidation, Cys carbamidomethylation, and Asn, Ser, Thr HexNAcylation, or Modification set 2 - Met and Pro oxidation, Glu, Asp and peptide C-term amidation, Cys carbamidomethylation, and the following on Pro residues: 1Hyp1HexOPent, 1Hyp2Hex0Pent, 1 Hyp3HexOPent, 1Hyp4HexOPent, 1Hyp0Hex1Pent, 1Hyp0Hex2Pent, 1Hyp0Hex3Pent, 1Hyp0Hex4Pent, 1Hyp1Hex1Pent, 1Hyp1Hex2Pent, 1Hyp1Hex3Pent, 1Hyp1Hex3Pent, 1Hyp2Hex0Pent, 1Hyp2Hex1Pent, 1Hyp2Hex2Pent, 1Hyp3Hex1Pent where Hyp = Hydroxyproline, Hex = hexose, Pent = pentose. Trypsin Cterminal cleavage specificity was set to "semi-specific C-ragged" at "KR" sites to identify C-terminal nontryptic proteolysis sites and subsequent C-terminal peptide amidation. Peptide output option was set to "automatic score cut" to allow 0-5\% peptide level FDR filtering and protein FDR was set to 1\%. All other parameters were kept at default settings. Scaffold v4 or v5 (Proteome Software, Inc., Portland, OR) were used for visualization and further analysis.

For comparative proteomics of VLE1 and SUB14, vegetative and gametic cilia were obtained from both mating types by the dibucaine method (see above). Isolated cilia were separated into membrane/matrix and axonemal fractions by extraction with 1\% IGEPAL CA-630 and differential centrifugation. Samples were electrophoresed in triplicate using a short SDS-PAGE gel protocol, stained with Coomassie blue and then subject to tryptic digestion. Tandem MS/MS spectra of purified tryptic peptides were obtained at the University of Massachusetts Medical School mass spectrometry facility and analyzed using Mascot with a parent ion tolerance of $10.0 \mathrm{ppm}$ and a fragment tolerance of $0.050 \mathrm{Da}$. Modifications allowed included carbamidomethyl on Cys, C-terminal minus Gly plus amide, N-terminal pyroglutamylation, methionine oxidation, N-terminal acetylation and phosphorylation.

\section{Bioinformatics analysis and structural modeling}

The signal peptide was identified using Signal P (www.cbs.dtu.dk/services/SignalP/) and N-glycosylation sites were predicted with NetNGlyc (www.cbs.dtu.dk/services/NetNGlyc/). The structural models for proGATI and VLE1 were generated using RoseTTAFold (https://robetta.bakerlab.org) (Baek et al., 2021). 
671 Structures were displayed using PyMOL (Schrödinger LLC). Structural homologues of individual proGATI 672 domains were identified using DALI (http://ekhidna2.biocenter.helsinki.fi/dali/; (Holm, 2020)).

673 Statistics and quantification

674 For each experiment, the number of biological replicates is indicated in the Figure Legend. One-way 675 ANOVAs with Tukey's multiple comparison test and two-way ANOVAs with Bonferroni post-tests were used 676 to compare the means. Results are represented as mean \pm SEM or \pm range as indicated in the Figure Legend. 677 GraphPad Prism 5 software was used to perform all statistical analyses.

\section{Acknowledgements}

680 We gratefully acknowledge the quantitative proteomics analysis conducted by Dr. Jeremy L. Balsbaugh, Director of the Proteomics \& Metabolomics Facility, a component of the Center for Open Research Resources and Equipment at the University of Connecticut. We also thank Maya Yankova for assistance with electron microscopy, Dr. Miho Sakato-Antoku for preparing vegetative and gametic cilia samples for mass spectrometry and assistance with chromatography, and Dr. R. Bloodgood (University of Virginia) for the gift of FMG-1 antibody.

\section{Funding}

This study was supported by National Institutes of Health grants RO1-DK032949 (to BAE), RO1-GM125606 (to SMK and BAE) and R35-GM140631 (to SMK); mass spectrometry of cilia samples was supported by RO1-GM051293 (to SMK).

\section{References} signalling by primary cilia in development, organ function and disease. Nat Rev Nephrol 15, 199-219. L. N., Schaeffer, R. D. et al. (2021). Accurate prediction of protein structures and interactions using a three-track neural network. Science 373, 871-876.

698 Bloodgood, R. A., Woodward, M. P. and Salomonsky, N. L. (1986). Redistribution and shedding of flagellar membrane glycoproteins visualized using an anti-carbohydrate monoclonal antibody and concanavalin A. J Cell Biol 102, 1797-812. Structural analysis of linear hydroxyproline-bound O-glycans of Chlamydomonas reinhardtii conservation of the inner core in Chlamydomonas and land plants. Carbohydrate Res 342, 2557-2566.

Bonnemaison, M. L., Bäck, N., Duffy, M. E., Ralle, M., Mains, R. E. and Eipper, B. A. (2015). Adaptor Protein-1 Complex Affects the Endocytic Trafficking and Function of Peptidylglycine a-Amidating Monooxygenase, a Luminal Cuproenzyme. J Biol Chem 290, 21264-79.

708 Cao, M., Ning, J., Hernandez-Lara, C. I., Belzile, O., Wang, Q., Dutcher, S. K., Liu, Y. and Snell, W. J. (2015). Uni-directional ciliary membrane protein trafficking by a cytoplasmic retrograde IFT motor and ciliary ectosome shedding. elife 4, e05242. 
Carvalho-Santos, Z., Azimzadeh, J., Pereira-Leal, J. B. and Bettencourt-Dias, M. (2011). Tracing the origins of centrioles, cilia, and flagella. J Cell Biol 195, 341-341.

Ding, K., Han, Y., Seid, T. W., Buser, C., Karigo, T., Zhang, S., Dickman, D. K. and Anderson, D. J. (2019). Imaging neuropeptide release at synapses with a genetically engineered reporter. eLife 8, e46421. Drucker, D. J. (2018). Mechanisms of Action and Therapeutic Application of Glucagon-like Peptide-1. Cell Metab 27, 740-756.

Fukada, K., Inoue, T. and Shiraishi, H. (2006). A posttranslationally regulated protease, VheA, is involved in the liberation of juveniles from parental spheroids in Volvox carteri. Plant Cell 18, 2554-66.

Glembotski, C. C., Dixon, J. E. and Gibson, T. R. (1988). Secretion of atrial natriuretic factor-(1-98) by primary cardiac myocytes. J Biol Chem 263, 16073-81.

Green, J. A., Schmid, C. L., Bley, E., Monsma, P. C., Brown, A., Bohn, L. M. and Mykytyn, K. (2016). Recruitment of $\beta$-Arrestin into Neuronal Cilia Modulates Somatostatin Receptor Subtype 3 Ciliary Localization. Mol Cell Biol 36, 223-235.

Halban, P. A. (1991). Structural domains and molecular lifestyles of insulin and its precursors in the pancreatic Beta cell. Diabetologia 34, 767-778.

Harris, E. (2009). The Chlamydomonas Sourcebook. San Diego: Elsevier. Holm, L. (2020). Using Dali for Protein Structure Comparison. Methods Mol Biol 2112, 29-42.

Huang, K., Kunkel, T. and Beck, C. F. (2004). Localization of the Blue-Light Receptor Phototropin to the Flagella of the Green Alga Chlamydomonas reinhardtii. Mol Biol Cell 15, 3605-3614.

Hughes, J. W., Cho, J. H., Conway, H. E., DiGruccio, M. R., Ng, X. W., Roseman, H. F., Abreu, D., Urano, F. and Piston, D. W. (2020). Primary cilia control glucose homeostasis via islet paracrine interactions. Proc Natl Acad Sci USA 117, 8912-8923.

Joshi, H. J., Narimatsu, Y., Schjoldager, K. T., Tytgat, H. L. P., Aebi, M., Clausen, H. and Halim, A. (2018). SnapShot: O-Glycosylation Pathways across Kingdoms. Cell 172, 632-632.e2.

Kawaharada, Y., Kelly, S., Nielsen, M. W., Hjuler, C. T., Gysel, K., Muszyński, A., Carlson, R. W., Thygesen, M. B., Sandal, N., Asmussen, M. H. et al. (2015). Receptor-mediated exopolysaccharide perception controls bacterial infection. Nature 523, 308-12.

King, S. M. (1995). Large-scale isolation of Chlamydomonas flagella. Methods Cell Biol 47, 9-12.

Kinoshita, T., Fukuzawa, H., Shimada, T., Saito, T. and Matsuda, Y. (1992). Primary structure and expression of a gamete lytic enzyme in Chlamydomonas reinhardtii: similarity of functional domains to matrix metalloproteases. Proc Natl Acad Sci USA 89, 4693-7.

Kubo, T., Kaida, S., Abe, J., Saito, T., Fukuzawa, H. and Matsuda, Y. (2009). The Chlamydomonas hatching enzyme, sporangin, is expressed in specific phases of the cell cycle and is localized to the flagella of daughter cells within the sporangial cell wall. Plant Cell Physiol 50, 572-83.

Kumar, D., Blaby-Haas, C. E., Merchant, S. S., Mains, R. E., King, S. M. and Eipper, B. A. (2016a). Early eukaryotic origins for cilia-associated bioactive peptide-amidating activity. J Cell Sci 129, 943-56.

Kumar, D., Mains, R. E. and Eipper, B. A. (2016b). 60 years of POMC: From POMC and $\alpha$-MSH to PAM, molecular oxygen, copper, and vitamin C. J Mol Endocrinol 56, T63-76.

Kumar, D., Mains, R. E., Eipper, B. A. and King, S. M. (2019). Ciliary and cytoskeletal functions of an ancient monooxygenase essential for bioactive amidated peptide synthesis. Cell Mol Life Sci 76, 23292348.

Kumar, D., Strenkert, D., Patel-King, R. S., Leonard, M. T., Merchant, S. S., Mains, R. E., King, S. M., Eipper, B. A. (2017). A bioactive peptide amidating enzyme is required for ciliogenesis. elife 6, e25728.

Kumar, D., Thomason, R. T., Yankova, M., Gitlin, J. D., Mains, R. E., Eipper, B. A. and King, S. M. (2018). Microvillar and ciliary defects in zebrafish lacking an actin-binding bioactive peptide amidating enzyme. Scientific Rep 8, 4547.

Long, H. and Huang, K. (2020). Transport of Ciliary Membrane Proteins. Frontiers Cell Dev Biol 7. 
Long, H., Zhang, F., Xu, N., Liu, G., Diener, D. R., Rosenbaum, J. L. and Huang, K. (2016). Comparative Analysis of Ciliary Membranes and Ectosomes. Curr Biol 26, 3327-3335.

Lopez-Moya, F., Suarez-Fernandez, M. and Lopez-Llorca, L. V. (2019). Molecular Mechanisms of Chitosan Interactions with Fungi and Plants. Int J Mol Sci 20.

Luxmi, R., Blaby-Haas, C., Kumar, D., Rauniyar, N., King, S. M., Mains, R. E. and Eipper, B. A. (2018). Proteases Shape the Chlamydomonas Secretome: Comparison to Classical Neuropeptide Processing Machinery. Proteomes 6, 36.

Luxmi, R., Kumar, D., Mains, R. E., King, S. M. and Eipper, B. A. (2019). Cilia-based peptidergic signaling. PLoS Biol 17, e3000566.

Luxmi, R., Mains, R. E., King, S. M. and Eipper, B. A. (2021). Peptidylglycine $\alpha$-Amidating Monooxygenase (PAM). In Encyclopedia of Biological Chemistry III (Third Edition), (ed. J. Jez), pp. 88-104. Oxford: Elsevier. Malicki, J. J. and Johnson, C. A. (2017). The cilium: cellular antenna and central processing unit. Trends Cell Biol 27, 126-140.

Marshall, W. and Basto, R. (2017). Cilia. Cold Spring Harbor, NY: Cold Spring Harbor Laboratory Press.

Mathieu-Rivet, E., Mati-Baouche, N., Walet-Balieu, M.-L., Lerouge, P. and Bardor, M. (2020). N- and OGlycosylation Pathways in the Microalgae Polyphyletic Group. Frontiers Plant Sci 11, 609993-609993.

Matsubayashi, Y. (2011). Post-Translational Modifications in Secreted Peptide Hormones in Plants. Plant Cell Physiol 52, 5-13.

Matsuda, Y., Koseki, M., Shimada, T. and Saito, T. (1995). Purification and Characterization of a Vegetative Lytic Enzyme Responsible for Liberation of Daughter Cells during the Proliferation of Chlamydomonas reinhardtii. Plant Cell Physiol 36, 681-689.

Miller, M. B., Yan, Y., Machida, K., Kiraly, D. D., Levy, A. D., Wu, Y. I., Lam, T. T., Abbott, T., Koleske, A. J., Eipper, B. A. et al. (2017). Brain Region and Isoform-Specific Phosphorylation Alters Kalirin SH2 Domain Interaction Sites and Calpain Sensitivity. ACS Chem Neurosci 8, 1554-1569.

Nachury, M. V. and Mick, D. U. (2019). Establishing and regulating the composition of cilia for signal transduction. Nat Rev Mol Cell Biol 20, 389-405.

Palma, M. S. (2006). Insect Venom Peptides. In Handbook of Biologically Active Peptides, (ed. A. J. Kastin), pp. 389-396. Burlington: Academic Press.

Ranjan, P., Awasthi, M. and Snell, W. J. (2019). Transient Internalization and Microtubule-Dependent Trafficking of a Ciliary Signaling Receptor from the Plasma Membrane to the Cilium. Curr Biol 29, 29422947.e2.

Reiter, J. F. and Leroux, M. R. (2017). Genes and molecular pathways underpinning ciliopathies. Nat Rev Mol Cell Biol 18, 533-547.

Rowe, M. L. and Elphick, M. R. (2012). The neuropeptide transcriptome of a model echinoderm, the sea urchin Strongylocentrotus purpuratus. Gen Comp Endocrinol 179, 331-44.

Sasso, S., Stibor, H., Mittag, M. and Grossman, A. R. (2018). From molecular manipulation of domesticated Chlamydomonas reinhardtii to survival in nature. eLife 7, e39233.

Schulze, S., Oltmanns, A., Machnik, N., Liu, G., Xu, N., Jarmatz, N., Scholz, M., Sugimoto, K., Fufezan, C., Huang, K. et al. (2017). N-Glycoproteomic Characterization of Mannosidase and Xylosyltransferase Mutant Strains of Chlamydomonas reinhardtii. Plant Physiol 176, 1952-1964.

Shakya, M. and Lindberg, I. (2020). Mouse Models of Human Proprotein Convertase Insufficiency. Endocrine Rev 42, 259-294.

Szabó, R., Láng, O., Láng, J., Illyés, E., Kőhidai, L. and Hudecz, F. (2015). Effect of SXWS/WSXWS peptides on chemotaxis and adhesion of the macrophage-like cell line J774. J Mol Recognition 28, 253-260.

Takahashi, T., Muneoka, Y., Lohmann, J., Lopez de Haro, M. S., Solleder, G., Bosch, T. C., David, C. N., Bode, H. R., Koizumi, O., Shimizu, H. et al. (1997). Systematic isolation of peptide signal molecules regulating development in hydra: LWamide and PW families. Proc Natl Acad Sci USA 94, 1241-6. 


40

Takao, D. and Verhey, K. J. (2016). Gated entry into the ciliary compartment. Cellular and molecular life sciences : Cell Mol Life Sci 73, 119-127.

Tan, L., Leykam, J. F. and Kieliszewski, M. J. (2003). Glycosylation motifs that direct arabinogalactan addition to arabinogalactan-proteins. Plant Physiol 132, 1362-9. van Dam, T. J. P., Kennedy, J., van der Lee, R., de Vrieze, E., Wunderlich, K. A., Rix, S., Dougherty, G. W., Lambacher, N. J., Li, C., Jensen, V. L. et al. (2019). CiliaCarta: An integrated and validated compendium of ciliary genes. PLoS One 14, e0216705.

Voigt, J., Woestemeyer, J. and Frank, R. (2007). The Chaotrope-soluble Glycoprotein GP2 Is a Precursor of the Insoluble Glycoprotein Framework of the Chlamydomonas Cell Wall*. J Biol Chem 282, 3038130392.

Wang, J., Silva, M., Haas, Leonard A., Morsci, Natalia S., Nguyen, Ken C. Q., Hall, David H. and Barr, Maureen M. (2014). C. elegans Ciliated Sensory Neurons Release Extracellular Vesicles that Function in Animal Communication. Curr Biol 24, 519-525.

Wang, Y., Bernard, A., Comblain, F., Yue, X., Paillart, C., Zhang, S., Reiter, J. F. and Vaisse, C. (2021). Melanocortin 4 receptor signals at the neuronal primary cilium to control food intake and body weight. $J$ Clin Invest 131.

Witman, G. B. (1986). Isolation of Chlamydomonas flagella and flagellar axonemes. Methods Enzymol 134, 280-290.

Wong, J., Gysel, K., Birkefeldt, T. G., Vinther, M., Muszyński, A., Azadi, P., Laursen, N. S., Sullivan, J. T., Ronson, C. W., Stougaard, J. et al. (2020). Structural signatures in EPR3 define a unique class of plant carbohydrate receptors. Nat Commun 11, 3797.

Wood, C. R., Huang, K., Diener, D. R. and Rosenbaum, J. L. (2013). The cilium secretes bioactive ectosomes. Curr Biol 23, 906-911.

Wu, C. T., Hilgendorf, K. I., Bevacqua, R. J., Hang, Y., Demeter, J., Kim, S. K. and Jackson, P. K. (2021). Discovery of ciliary $\mathrm{G}$ protein-coupled receptors regulating pancreatic islet insulin and glucagon secretion. Genes Dev 35, 1243-1255.

Xu, N., Oltmanns, A., Zhao, L., Girot, A., Karimi, M., Hoepfner, L., Kelterborn, S., Scholz, M., Beißel, J., Hegemann, P. et al. (2020). Altered N-glycan composition impacts flagella-mediated adhesion in Chlamydomonas reinhardtii. elife 9, e58805.

Yasuda, A., Jones, L. and Shigeri, Y. (2013). The Multiplicity of Post-Translational Modifications in ProOpiomelanocortin-Derived Peptides. Frontiers Endocrinol 4, 186.

8

9

41

42

3


A.

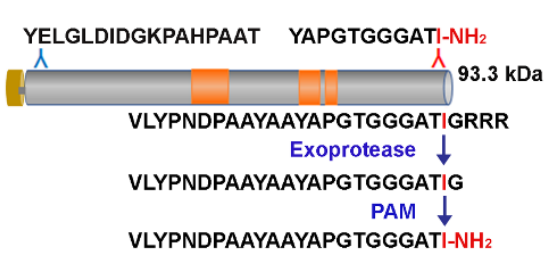

D. IPTs:C-ter Ab

Blot:C-ter Ab Ectosomes

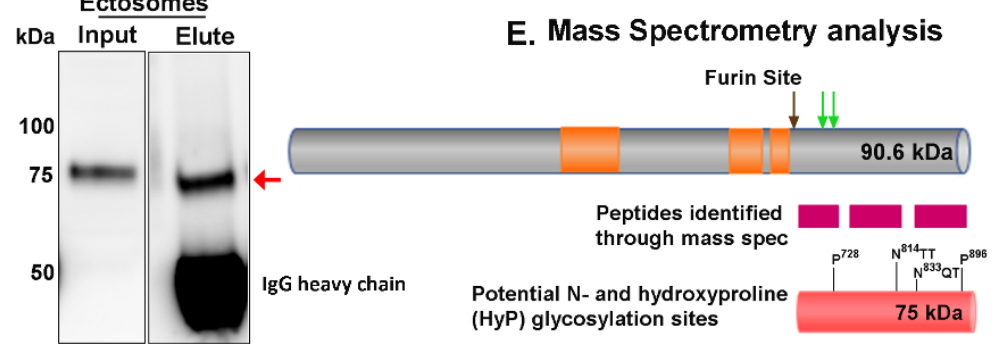

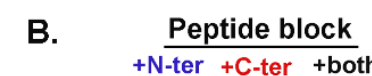
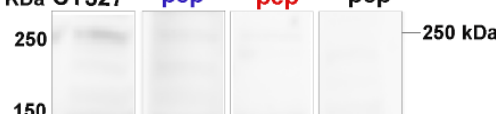

\begin{tabular}{l|l|l|}
\hline & $-150 \mathrm{kDa}$ \\
\hline & -120
\end{tabular}

100

75

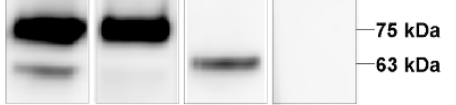

E. Mass Spectrometry analysis

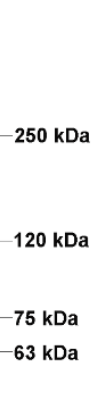

KDa CT327 $\begin{gathered}+\mathrm{N}-\text {-ter } \\ + \text { pep }\end{gathered}$

HyP) glycosylation sites
GATI-NH $\mathrm{H}_{2}$-VLYPNDPAAYAAYAPGTGGGATI-NH $\mathrm{N}_{2}$ GATI-GIY - VLYPNDPAAYAAYAPGTGGGATI-Gly GATI-OH -VLYPNDPAAYAAYAPGTGGGATI-OH

\section{F. Identified C-ter peptides}

----RFSRMEAAGALGSNKRVVWWTDGDFESORK. AVWNSPLNLVWRGKAACGKCGACGRAWKPRGDKF SVQLFFREPVQLDEIRIRQVWHAGVTEVRLLAWP AVDAVNRVSDVFLGEPVLRQTADNTTCNTWLTVA IPQERAGTNQTVRPIGSQDAIPPKLRSSTVGGVV ITTRTAATVRAGTWIDAVDFSGRVLYPNDPAAYA AYAPGTGGGATI-NH

Figure 1. Cre03.g204500 in mating ectosomes. A. Diagram shows Cre03.g204500 (preproGATI) and the $\mathrm{N}$-terminal and $\mathrm{C}$-terminal peptides used as antigens and for peptide blocking. The Pro-rich regions are in orange. The pathway leading to C-terminal amidation is illustrated. B. Mating ectosomes (10 $\mu \mathrm{g}$ protein) isolated from $1 \mathrm{~h}$ mixed gametes were fractionated by SDS-PAGE, blotted and incubated with antiserum (CT327) alone or following pre-incubation with the N-ter (blue), C-ter (red) or mixture of both (black) antigenic peptides. Approximate molecular masses are shown. Data are representative of three independent experiments. C. The proGATI antibody generated is amidation specific. Immunoblot of mating ectosomes $\left(10 \mu \mathrm{g} /\right.$ lane) probed with $\mathrm{CT} 327$ antiserum pre-incubated with peptides having $-\mathrm{NH}_{2}$ (GATI-amide), -Gly (GATI-Gly) or -OH (GATI-OH) at the C-terminus. Red arrowheads indicate that the signals for the 250-kDa and 75-kDa bands are almost completely blocked by GATI-NH 2 peptide, attenuated by GATI-Gly and unaffected by GATI-OH. Similar results were obtained in two independent experiments. D. Immunoprecipitation from mating ectosomes with affinity-purified C-ter antibody. The excised 75-kDa fragment (red arrow) was analyzed by mass spectrometry. E. The location of peptides identified by mass spectrometry is indicated (pink boxes). A furin-like cleavage site (black arrow) precedes the most $\mathrm{N}$ terminally located peptide identified; potential paired basic cleavage sites (green) and predicted $\mathrm{N}$ glycosylation and O-glycosylation sites are indicated. F. The C-terminal sequence of proGATI is shown. Peptides identified by mass spectrometry are in blue. The furin-like cleavage site (yellow highlight), paired basic residues (green), predicted $\mathrm{N}$-glycosylation sites (pink), predicted O-glycosylation sites (Pro residues subject to hydroxylation; orange) and amidated C-terminus (red) are indicated. 
A.ter
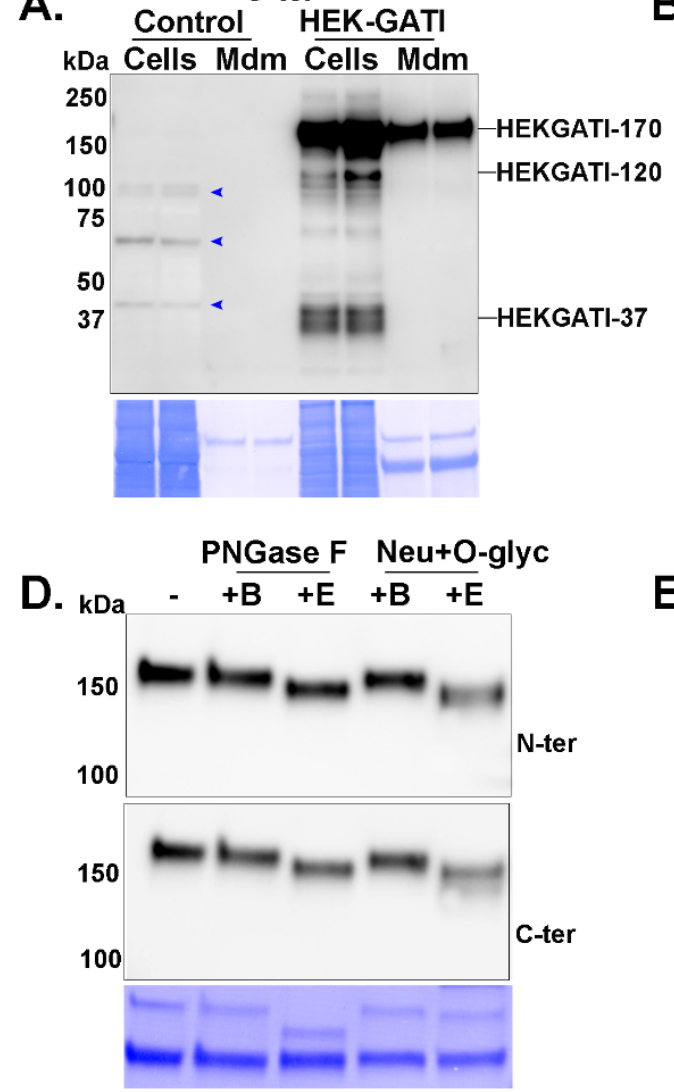

B.

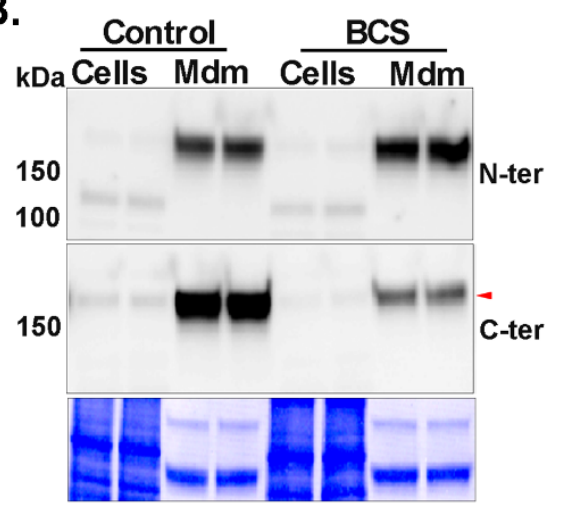

C.

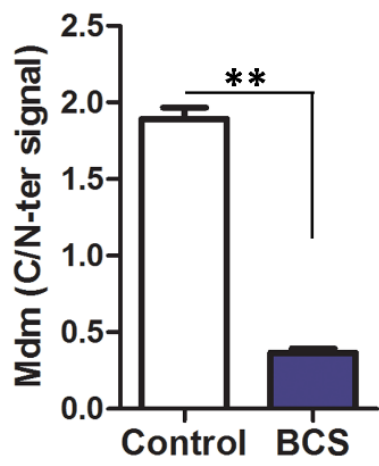

E.

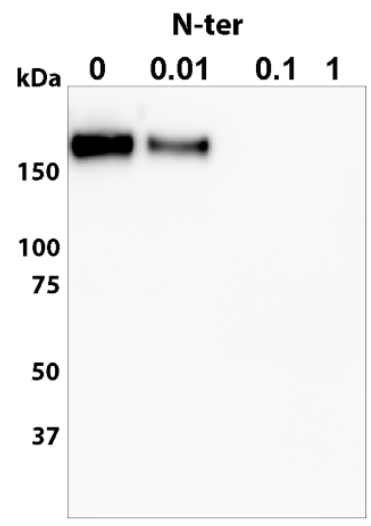

C-ter $\begin{array}{llll}0 & 0.01 & 0.1 & 1 \mu g\end{array}$ Trypsin

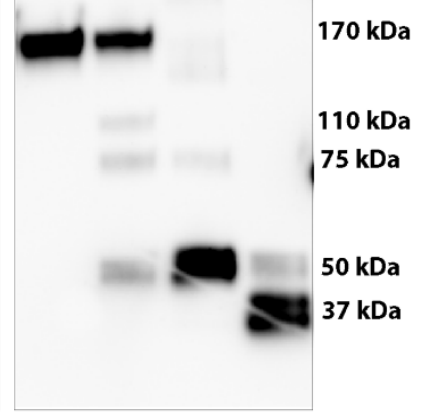

869

Figure 2. Expression of proGATI in HEK-293 cells. A. Immunoblot of cell extracts (Cells; $20 \mu \mathrm{g}$ protein, approximately $10 \%$ of total) and spent medium (Mdm; $1 \%$ of total collected over an $18 \mathrm{~h}$ period) of Control (non-transfected) and HEK-293 cells expressing preproGATI probed with affinity-purified C-ter antibody. A $170 \mathrm{kDa}$ (HEK-proGATI) band was detected in both cells and spent medium while $120 \mathrm{kDa}$ and $37 \mathrm{kDa}$ bands were detected only in cells (and see Fig. S2A). Non-specific bands identified in Controls are marked (blue arrow). Secretion rate and cell content are quantified in Fig. S2B. B. Analysis of C-terminal amidation of HEK-proGATI. Spent medium (5\%) and cell lysates ( $15 \mu \mathrm{g}, \sim 20 \%$ of total) of BCS-treated cells and their respective Controls were analyzed. The C-ter signal for HEK-proGATI was reduced following BCS treatment (red arrow), whereas the N-ter signal was unaffected. C. The C-ter/N-ter signal ratio for HEKGATI-170 was reduced following BCS treatment. Results are the average of duplicates, where ${ }^{* *} \mathrm{P}<0.001$. D. HEK-proGATI spent medium $(10 \mu \mathrm{l})$ was digested with PNGase F or with a mixture of O-glycosidase and neuraminidase (Neu+O-glyc); no treatment (-), incubated in buffer alone (+B), or buffer with enzyme (+E). Reductions in the apparent molecular mass of secreted HEK-GATI-170 of 15-20 kDa were observed. Similar results were obtained in three independent experiments. E. Tryptic digestion of HEK-GATI in spent medium $(10 \mu \mathrm{l})$; samples were fractionated by SDS-PAGE and probed with $\mathrm{N}$-ter and C-ter antibodies. The $\mathrm{N}$-ter antigenic site contains a single Lys residue and is destroyed by trypsin treatment. The C-ter antibody detected the indicated tryptic products. The results were duplicated in independent experiments. 
A.

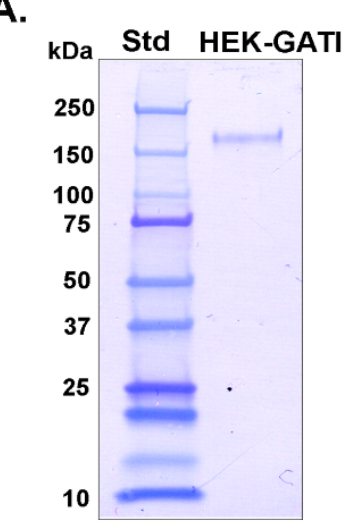

B.

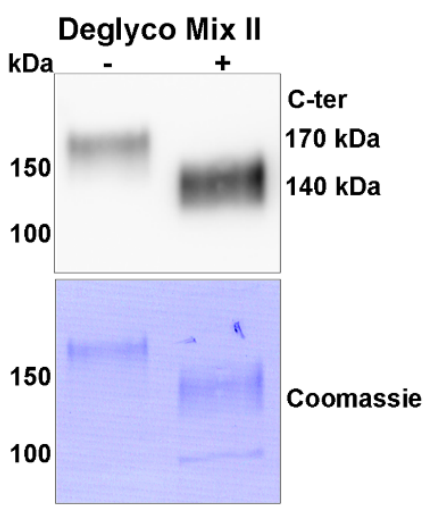

C.

\begin{tabular}{|c|c|c|c|}
\hline SN & PTM & Position & Motif \\
\hline 1 & N-glycosylation sites & N471 & NFS \\
\hline 2 & (Deamination of Asn) & N479 & NVT \\
\hline 3 & & N640 & NLT \\
\hline 4 & & N814 & NTT \\
\hline 5 & & N833 & NQT \\
\hline 6 & O-glycosylation sites & S237 & TSSAA \\
\hline 7 & & S245 & LSSAS \\
\hline 8 & & S571 & PSSVG \\
\hline 9 & & S622 & PPSPP \\
\hline 10 & 1Hyp1Hex0Pen & P350 & SMPDAV \\
\hline 11 & 1Hyp1Hex1Pen & P896 & YAPGTG \\
\hline 12 & Gly-loss + amide & I904 & \\
\hline
\end{tabular}
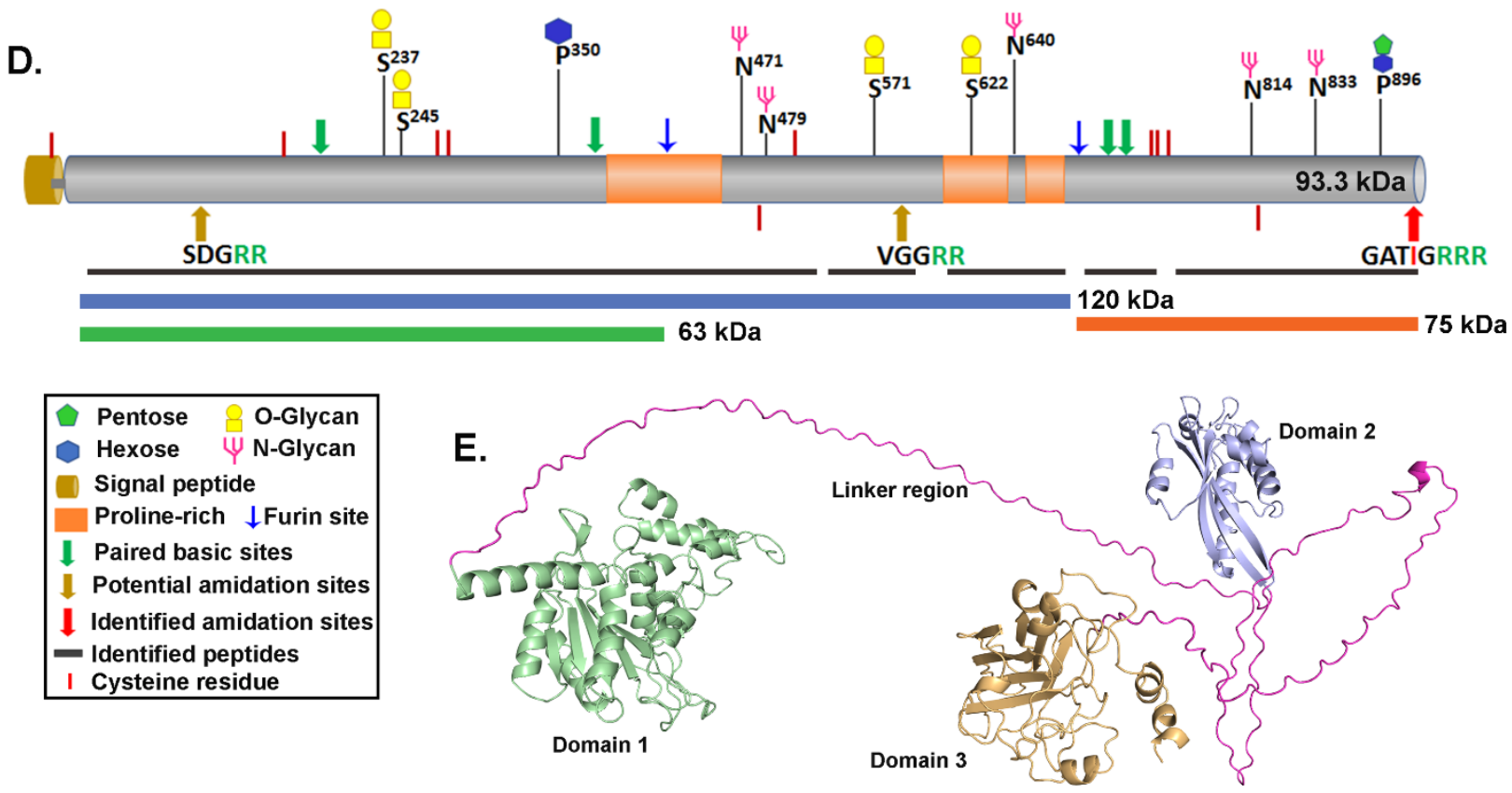

Figure 3. Mass spectrometry analysis of purified HEK-GATI-170. A. SDS-PAGE of purified HEK-proGATI (see Fig. S2C); Coomassie-stained PVDF membrane is shown. B. Digestion of purified HEK-proGATI with protein deglycosylation mix II reduced its apparent molecular mass. C. Glycosylation sites identified; Nglycosylation sites were identified in deglycosylated-HEK-proGATI, while O-glycosylation sites were identified in purified native protein. D. Schematic diagram of preproGATI illustrating the $\mathrm{N}$ - and $\mathrm{O}-$ glycosylation sites identified in purified HEK-proGATI. The predicted products resulting from cleavage at the furin-like sites are indicated. E. The structural model of proGATI generated using RoseTTAFold (Baek et al., 2021) contains three well-folded domains (domain 1, residues 51-370, green; domain 2, residues 446-593, blue; domain 3, residues 696-908, orange) connected by long, highly flexible, Pro-rich linkers (pink). Although individual domains are well structured, their relative orientation with respect to each other is variable. 
A.

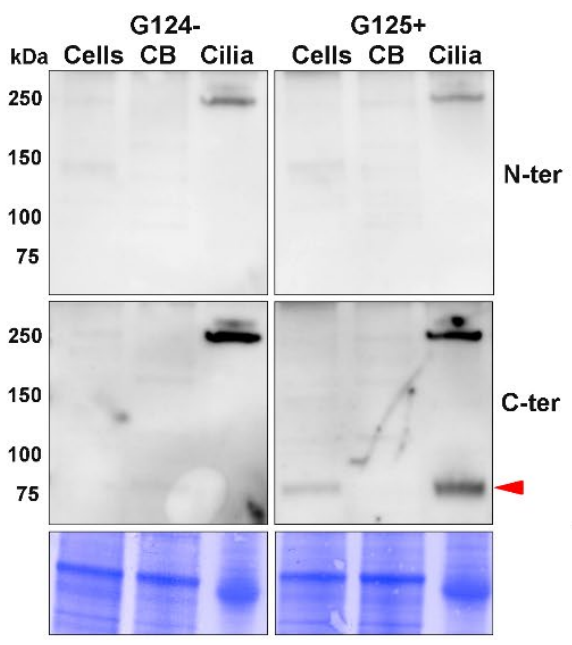

B.

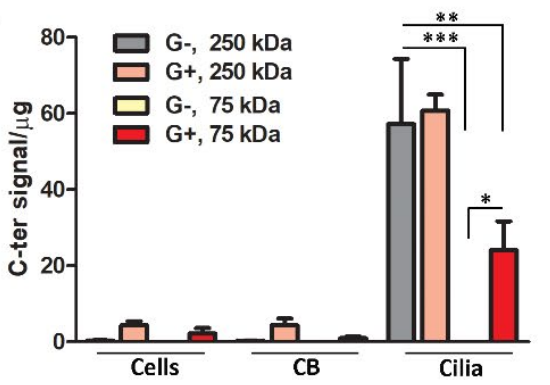

C.

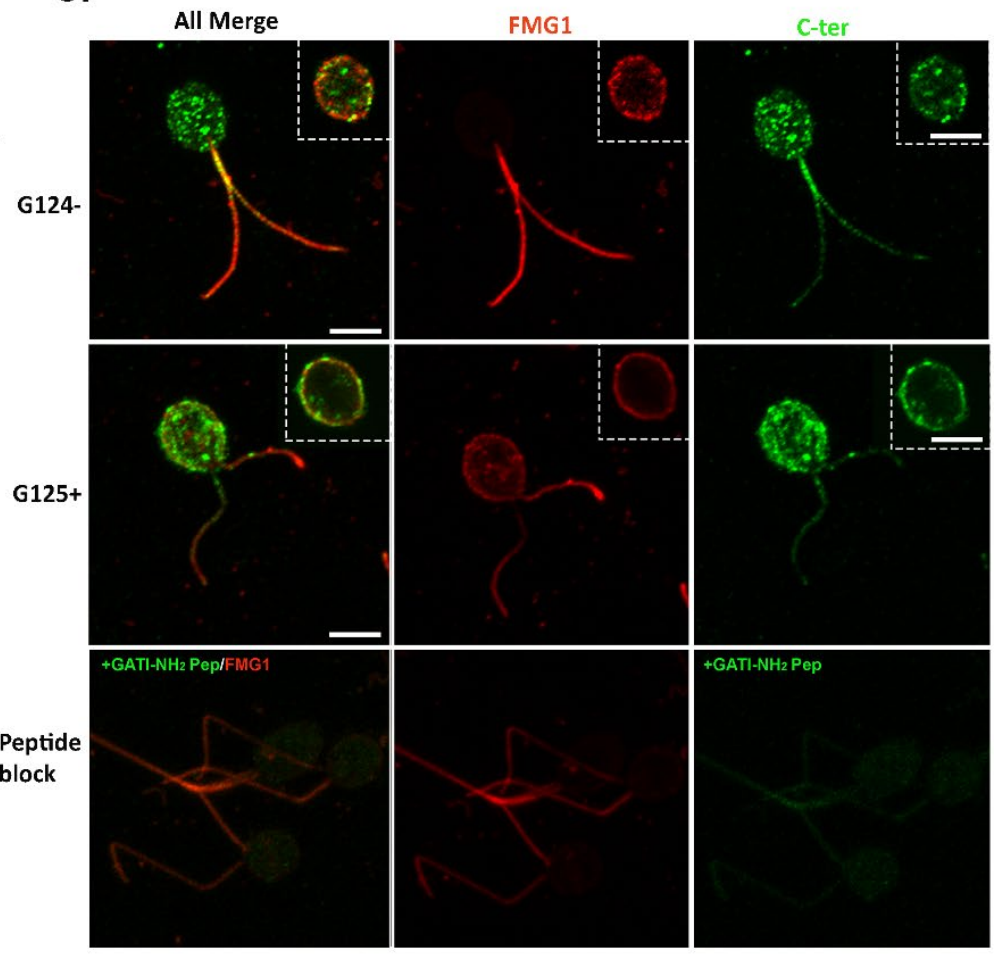

Figure 4. Processing and localization of proGATI in minus and plus gametes. A. Immunoblot of cells, deciliated cell bodies and cilia of minus (G124-) and plus (G125+) resting gametes using affinity-purified proGATI N-ter and C-ter antibodies. Equal amounts of protein $(20 \mu \mathrm{g})$ were loaded. B. Quantification of the C-ter signal for proGATI revealed significant enrichment of 250-kDa and 75-kDa bands in cilia but not in cell bodies (CB). Results are the average of duplicates. Means were compared with \pm range. Asterisks indicate significant differences between groups ${ }^{*} P<0.05,{ }^{*} P<0.01, * * * P<0.001$. C. Maximal projection confocal images of minus and plus resting gametes stained with the C-ter proGATI antibody (green) and antibody to FMG1 (red). Inset images show single Z-planes. Plus gametes probed with antibody preincubated with the GATI- $\mathrm{NH}_{2}$ peptide exhibit reduced staining (green) in cell bodies and cilia. Similar localization of proGATI in gametes was obtained in three independent experiments. Scale bar $=5 \mu \mathrm{m}$. 
A.

B.

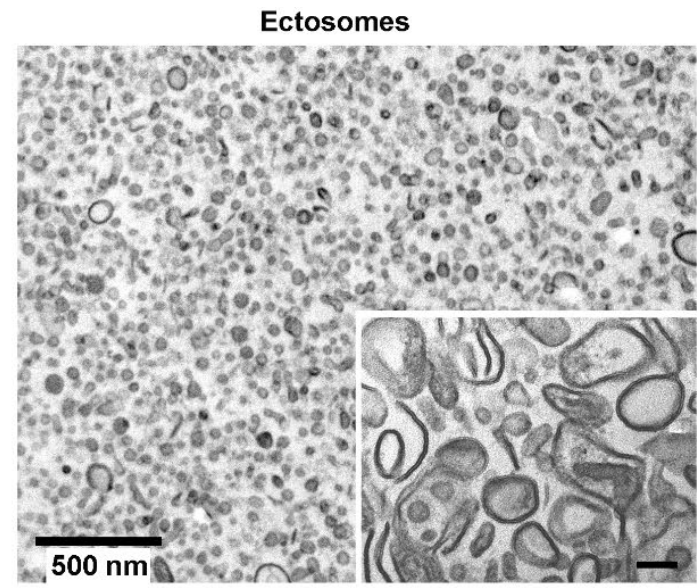

1h $-/+$ mixed gametes kDa CB Cilia Ecto

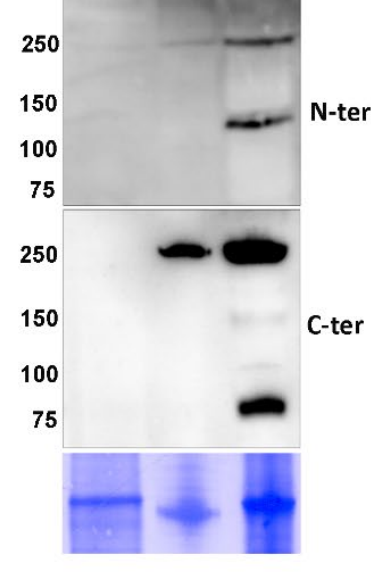

C.

C. $1 \mathrm{~h}-/+$ mixed gametes
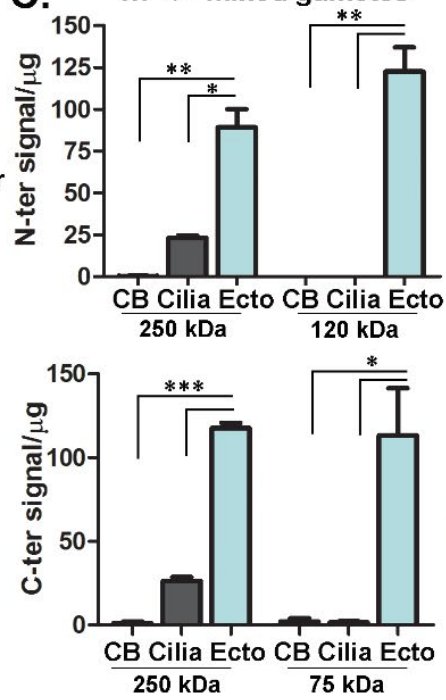

Negative control

N-ter

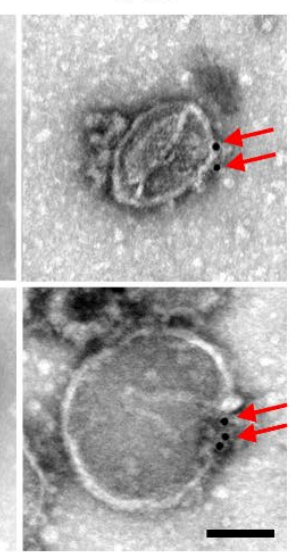

D.

CrPAM lu $-1+$ mixed gametes kDa Cells CB Cilia Ecto
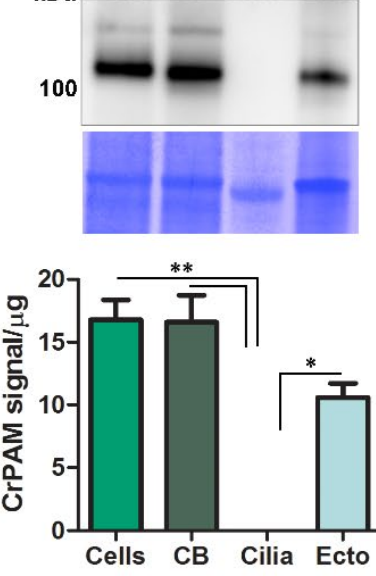

C-ter

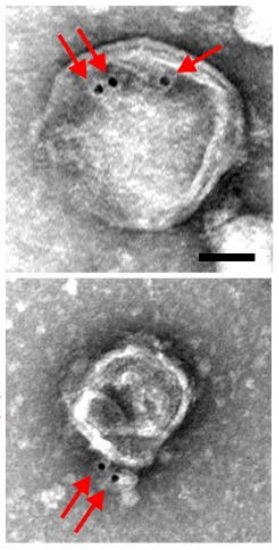

E.

FMG1

-1+ mixed gametes kDa Cells CB Cilia Ecto
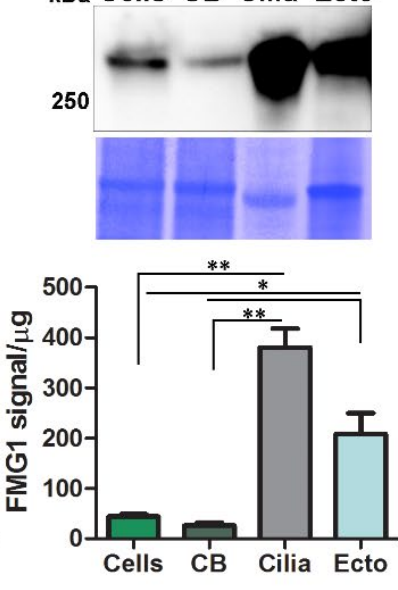

Figure 5. ProGATI in mating ectosomes. A. A cross-section transmission electron micrograph of an agarose embedded ectosome pellet isolated from $1 \mathrm{~h} \mathrm{-/+}$ mixed gametes is shown. The inset shows a higher magnification image of ectosomes that had been treated with $\mathrm{Na}_{2} \mathrm{CO}_{3}$ to remove peripheral membrane proteins; scale bar $=100 \mathrm{~nm}$. The right panels show immuno-gold-EM negative stain images of intact ectosomes incubated with affinity-purified N-ter or C-ter antibodies and a gold-tagged secondary antibody; both epitopes localized to the ectosomal surface. Ectosomes incubated with gold-tagged secondary anti-rabbit antibody alone served as a negative control; scale bars $=500 \mathrm{~nm}$ (main image) and $100 \mathrm{~nm}$ (inset). Images are representative of three independent experiments. B. The deciliated cell bodies (CB), cilia and ectosomes (Ecto) isolated from mixed gametes were fractionated by SDS-PAGE, blotted and probed with the N-ter and C-ter antibodies against proGATI. C. Graph showing the enrichment of N-ter and C-ter signals for proGATI and its fragments in ectosomes. Results are the average of two independent experiments; mean is \pm range. Asterisks indicate a statistically significant difference between two groups $\left({ }^{*} \mathrm{P}<0.05,{ }^{*} \mathrm{P}<0.001,{ }^{* * *} \mathrm{P}<0.0001\right)$. D \& E. Immunoblot analysis showing CrPAM and FMG1 levels in cells, cell bodies, cilia and ectosomes isolated from mixed gametes. Quantification of CrPAM and FMG1 protein levels is shown in the graphs. Results are average of duplicates and error bars indicate the \pm range (where $* \mathrm{P}<0.05, * * \mathrm{P}<0.001$ ). 
A.

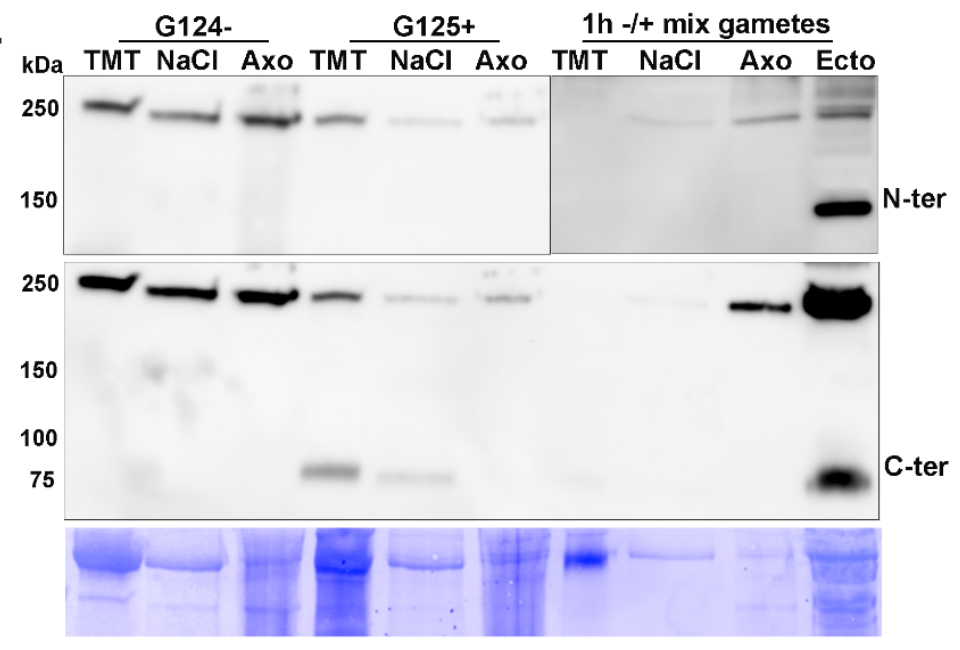

C.

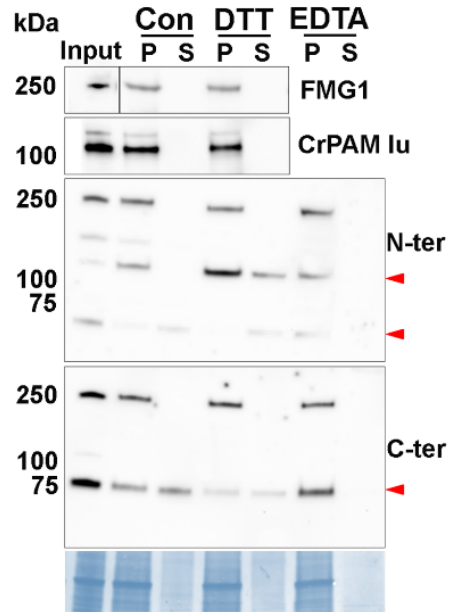

D.

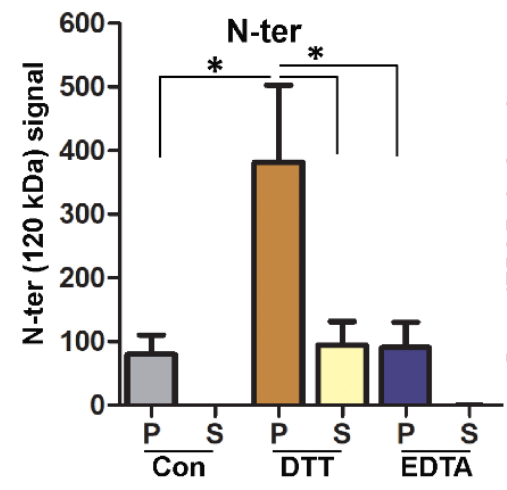

B. C-ter signal
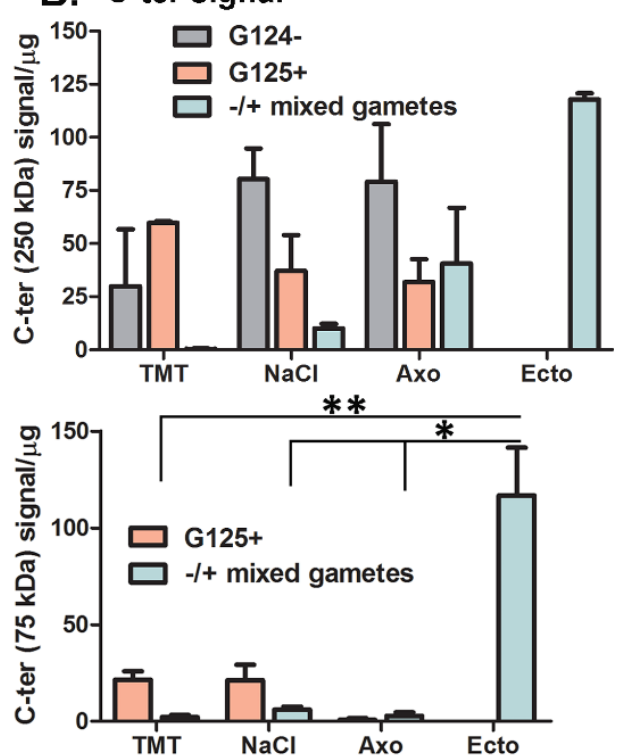

C-ter

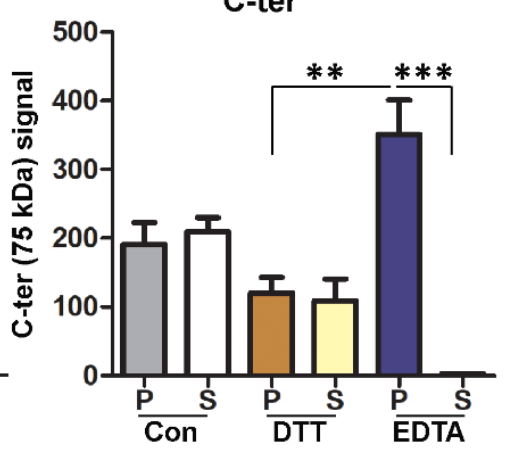

Figure 6. Ciliary localization and association of proGATI and its fragments with ectosomes. A. Cilia were sequentially treated with buffers containing $1 \%$ Triton X-100 (TMT) and $0.6 \mathrm{M} \mathrm{NaCl}(\mathrm{NaCl})$; the resulting axonemal pellet (Axo) was solubilized in $1 \%$ SDS-buffer. The sub-ciliary fractions from resting minus (G124) and plus (G125+) gametes mixed gametes and mating ectosomes (Ecto) were fractionated by SDS-PAGE, blotted and probed with affinity-purified $\mathrm{N}$-ter and C-ter antibodies. Equal amounts of protein (20 $\mu \mathrm{g})$ were loaded for each sample. B. Immunoblot quantification of the 250-kDa and 75-kDa C-ter products. Means are average of duplicates and error bars indicate \pm range, where ${ }^{*} P<0.05,{ }^{*} P<0.01$. C. Freshly isolated mating ectosomes (Input) were washed with buffer alone (10 mM HEPES, control) or with buffer containing $10 \mathrm{mM}$ dithiothreitol (DTT) or $10 \mathrm{mM}$ EDTA; after centrifugation, the resulting supernatants (S) and pellets $(\mathrm{P})$ were analyzed for the presence of proGATI (using N-ter and C-ter antibodies), PAM and FMG1. Red arrowheads mark the 120-kDa, 75-kDa and 63-kDa bands. Samples loaded represent the pellets and corresponding supernatants derived from an initial $15 \mu \mathrm{g}$ of ectosomes. D. Quantification of 120-kDa N-ter signal $(n=4)$ and $75-k D a C$-ter signal $(n=3)$; means \pm SEM are shown. Asterisks indicate significant differences between the groups, $* P<0.05, * * P<0.01, * * * P<0.001$. 
A
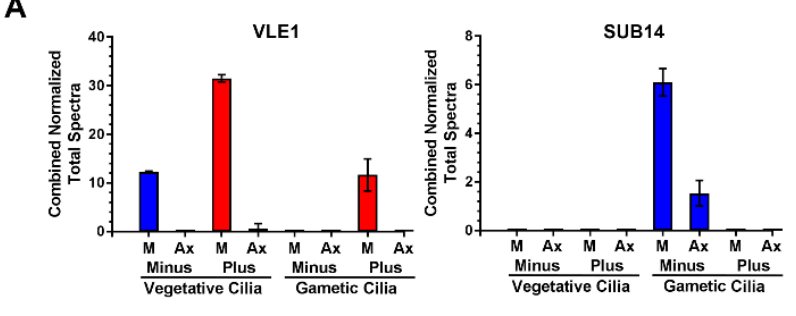

C

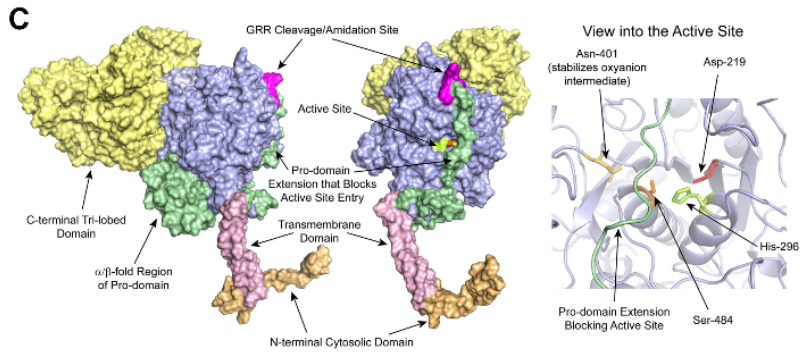

B

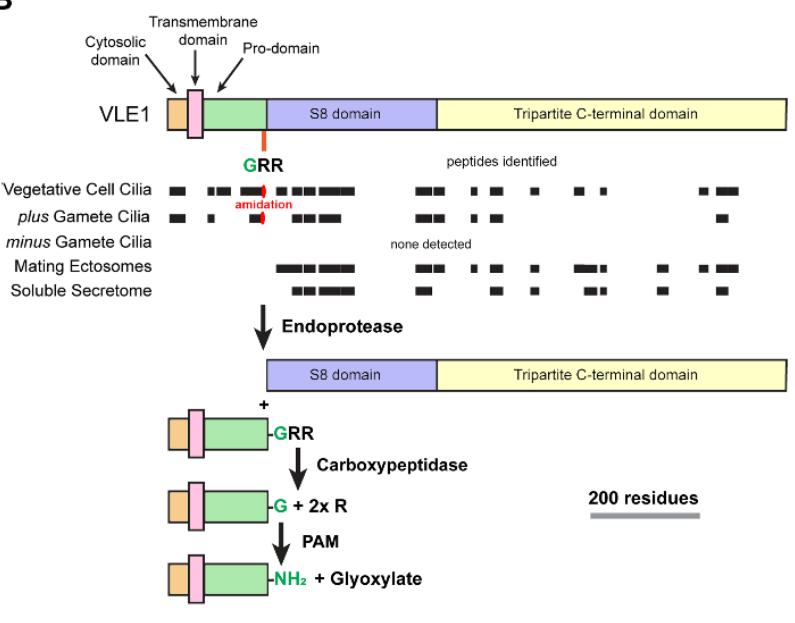

Figure 7. Ciliary distribution and processing of subtilisin-like proteases. A. Normalized total spectral counts of VLE1 and SUB14 in the ciliary membrane/matrix (M) and axonemal (Ax) fractions from minus and plus vegetative and gametic cilia (mean $\pm S E M ; n=3$ ). B. Diagram showing the cytosolic (light orange), transmembrane (pink), pro- (green), S8 (purple) and C-terminal (yellow) domains of VLE1. The I VLE1 peptides identified in the cilia of vegetative cells, plus and minus gametes and in mating ectosome and the soluble secretome are indicated by black boxes. The cleavage/amidation site (GRR) that immediately precedes the $\mathrm{S} 8$ catalytic domain is indicated. The processing pathway proposed for VLE1 is shown. The $\alpha$-amidated peptide (K)APTDITDPTAASSSS- $\mathrm{NH}_{2}$ produced by cleavage and amidation was found in both vegetative and plus gamete cilia. $\mathbf{C}$. Two views of the molecular surface of a structural model for VLE1 calculated using RoseTTAFold are shown. The protein consists of a short N-terminal cytosolic domain (light orange), a single transmembrane region (pink), an unusual pro-domain (green), the catalytic S8 domain (blue), and a large C-terminal domain (yellow) that has a tri-partite organization with each lobe consisting of two anti-parallel $\beta$ sheets which exhibit considerable structural similarity to the CEA1 Nacetylglucosamine-binding adhesin from the methylotrophic yeast Komagataella pastoris (z score $=11.8$, $\mathrm{RMSD}=4.0 \AA$; $5 \mathrm{~A} \mathrm{~L}$ ). The cleavage/amidation site is indicated in magenta. The right-hand panel shows a ribbon diagram of the active site. Side chains of the catalytic triad residues and the Asn that stabilizes the transition state are shown. The pro-domain strand that arches across the active site is indicated in green. 


\section{A}

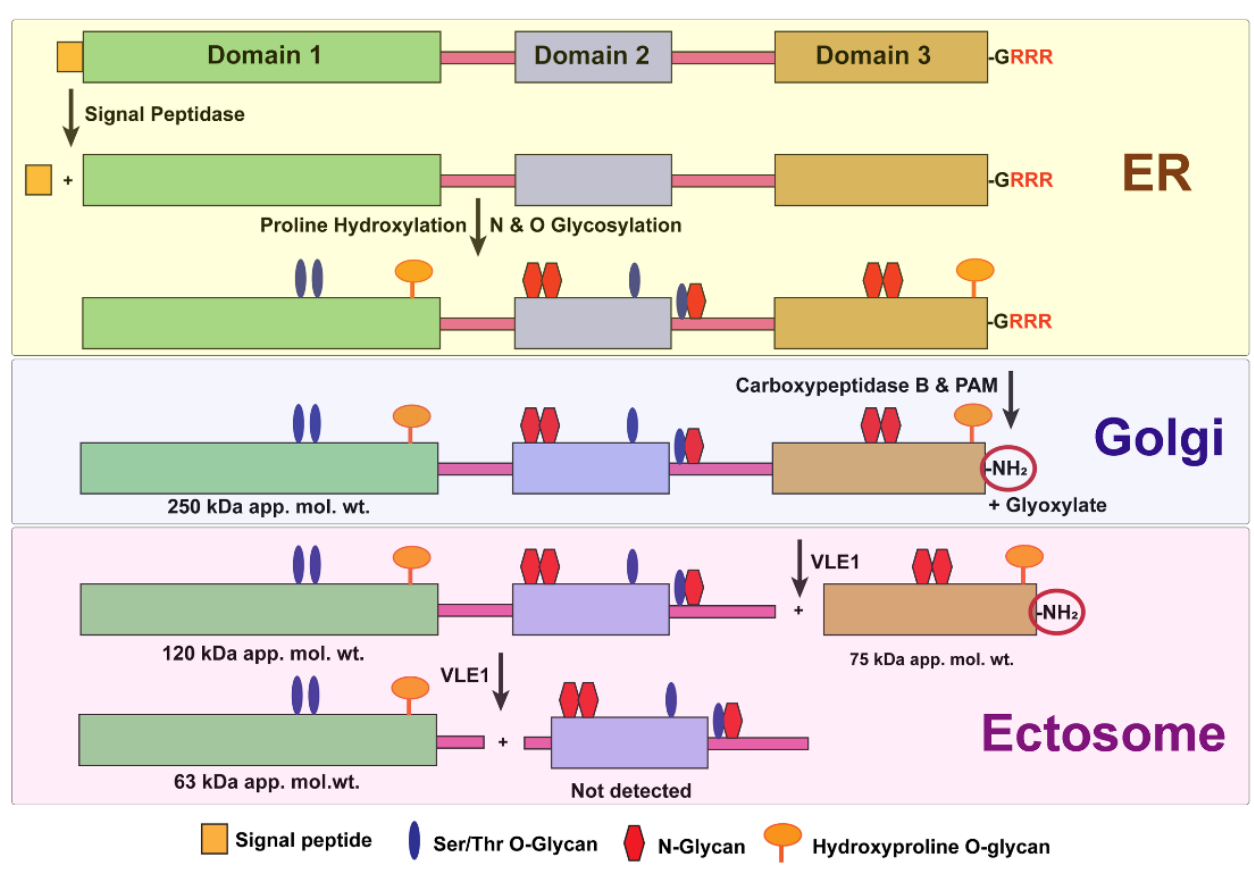

B

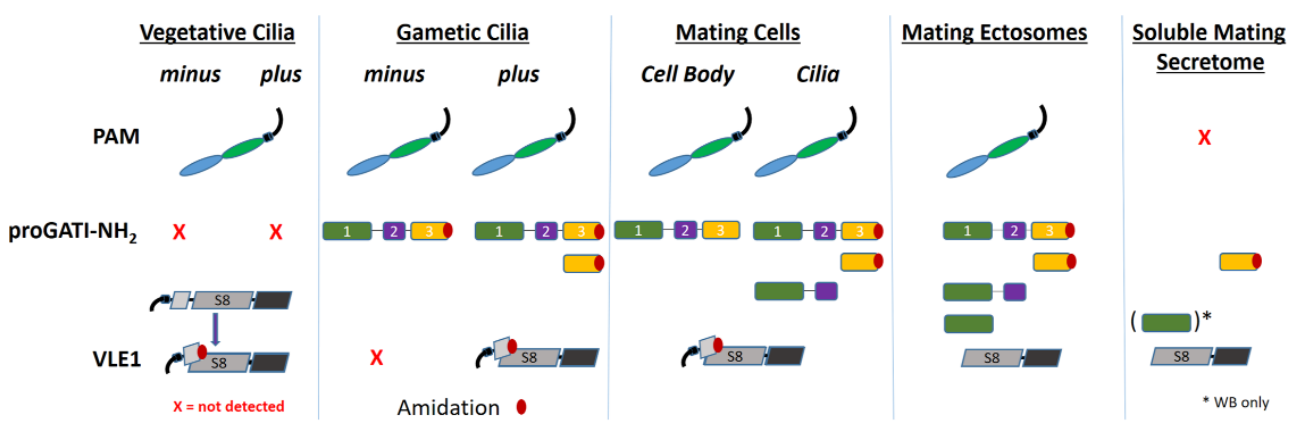

Figure 8. ProGATI processing pathway. A. Diagram illustrating the processing pathway of preproGATI that occurs as it traffics through the ER and Golgi and subsequently enters cilia and ectosomes. As preproGATI enters the ER, its signal peptide (orange box) is removed by signal peptidase. The addition of $\mathrm{N}$-linked sugars (red) begins in the ER, as does modification of Pro to HyP by prolyl hydroxylases. As proGATI moves into the Golgi complex, more complex sugars and O-linked sugars on HyP (orange) and Ser/Thr (blue) residues are added, leading to the higher apparent molecular mass ( $250 \mathrm{kDa}$ ) of proGATI. A carboxypeptidase trims the three $\mathrm{C}$-terminal Arg residues and generates a substrate for PAM. PAM converts the -Gly extended substrate into the amidated product $\left(\mathrm{GATI}-\mathrm{NH}_{2}\right)$ in a two-step reaction and releases glyoxylate as a byproduct. This $250-\mathrm{kDa}$ amidated proGATI form is then moved to the ciliary membrane. Once on cilia, or as it moves from cilia into nascent ectosomes, 250-kDa proGATI is cleaved by a subtilisin-like endoprotease (predicted to be VLE1) to yield the 120-kDa N-terminal region, and the amidated $75-k D a$ C-terminal fragment. Cleavage of the 120-kDa product at either a second furin-like cleavage site located in the linker between domains 1 and 2, or at a dibasic site at the C-terminal end of domain 1 , might then produce the 63-kDa N-terminal fragment and a second product containing domain

9752 for which no probe currently exists. B. Diagram illustrating the presence and absence (red cross) of PAM, 
976 the amidated peptide precursor (proGATI-NH${ }_{2}$ ) and its various fragments, and the cleaved/amidated

977 subtilisin-like endoprotease VLE1 in cilia of minus and plus vegetative and gametic cells, and in ectosomes

978 and the soluble secretome obtained from mating gametes. PAM is present in vegetative and gametic cell

979 cilia and is released into ectosomes but not into the secretome. In contrast, proGATI- $\mathrm{NH}_{2}$ is undetectable

980 in vegetative cilia and only appears following gametogenesis. The amidated C-terminal fragment is 981 generated in plus gamete cilia and released into ectosomes and the secretome during mating; other pro-

982 GATI products are also variably present in these samples. VLE1 is found in vegetative and plus gamete

983 cilia, but not in minus gamete cilia. All ciliary VLE1 is proteolytically processed within the pro-domain and

984 amidated. As VLE1 moves to ectosomes and is released into the soluble secretome, it undergoes a change

985 in domain architecture with the catalytic S8 and C-terminal domains dissociating from the amidated N-

986 terminal segment.

987

988

989

990

991

992

993

994

995

996

997

998

999

1000

1001

1002

1003

1004

1005 


\section{Supplemental Figures}

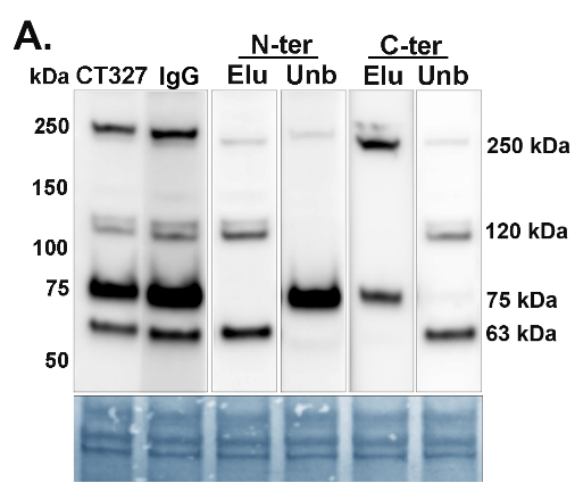

D.

\begin{abstract}
AHPAATIVSGDDSS LDGIALSRATTGGLLIVVGSPANLHKT I GAAFDVGSDGRRCDSTSNGG SVTHGSRPRLHAAAATLFGSEDALDAEWPQTLEAVAVTHSIAACNVGGAVTQVPLYFSPSDG SIVAVAFTSASPRKRTVVWLGYDWAAGPQTAWGAVLAKLIDTHALLTATSSAAAASLSSASS ATAGEPKVVHITTTSSSAAASNTGCGSGTCSHSHLVMATLAAAASSSAASASAASSSASTLA HTGGSETEFAADAAKDGDDAAAEPVLVDDAAMDAALDSMPDAVSDLSDGVSEVVRRMMAATT GAGTYPAPPSPEPASPAPPSPAPLTPAPPSPRPPKPRKSPPSPPTTPPPLAPPSPPSPPAPP SPPPPLPPGLAAEVQGYNSDTSAPPGFNISDTLSVQNFSRDFCENVTRALDPRPDECVVFDI KSHGGATHHHRLLSEAGALRVWGPEDLAAEHPALAAAGMSRLVHLRTYSVGEAELAAVRAWD LSVSLPVTALPSSVGGRRSLQQSTQTITLAFVVIYLVEVPLPPSPPPRAPNPPGVMEPPSPP PSPPAAPPHPPRSPPRPPVNLTALASAVGASAVYQVFPPPPSPPSPPSPMPPSPPPSPHPPP LPLADRITSVRFSRMEAAGALGSNKRVVWWTDGDFESQRKAVWNSPLNLVWRGKAACGKCGA CGRAWKPRGDKFSVQLFFREPVQLDEIRIRQVWHAGVTEVRLLAWPAVDAVNRVSDVFLGEP VLRQTADNTTCNTWLTVAIPQERAGTNQTVRPIGSQDAI PPKLRSSTVGGVVITTRTAATVR AGTWIDAVDFSGRVLYPNDPAAYAAYAPGTGGGATIGRR
\end{abstract}

.

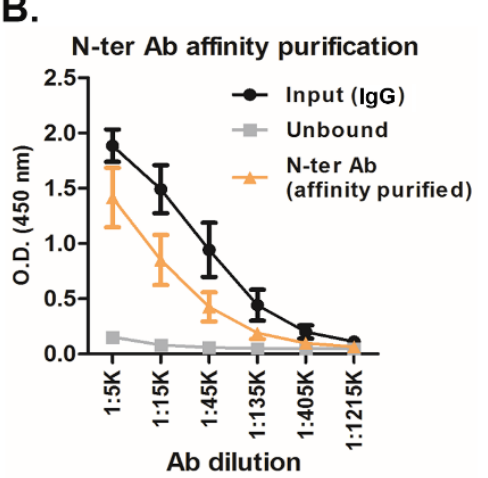

1008

1009

1010

1011

1012

1013

1014

1015

1016

1017

1018

1019

1020

1021

1022

1023

1024

1025

1026 replicated in independent experiments.

Figure S1. A. Immunoblots showing the results of affinity-purification of N-ter and C-ter proGATI antibodies. Mating ectosomes (15 $\mu \mathrm{g}$ protein) were fractionated by SDS-PAGE and individual PVDF strips incubated with serum from rabbit CT327, an immunoglobulin-enriched fraction prepared from this serum (IgG) or aliquots of the material that did not bind (unbound (Unb)) or was eluted from (Elu) columns that contained either the $\mathrm{N}$-ter or C-ter peptide linked to AffiGel. The 250-kDa, 120-kDa and 63-kDa bands were detected by the bound (affinity-purified) fraction of the $\mathrm{N}$-ter antibody and by the unbound fraction of the C-ter antibody. The 250-kDa and 75-kDa bands were detected by the bound (affinity-purified) fraction of the $\mathrm{C}$-ter antibody and by the unbound fraction of the $\mathrm{N}$-ter antibody. B and $\mathbf{C}$. The specificity and yield of the affinity-purified $\mathrm{N}$-ter and $\mathrm{C}$-ter antibodies was determined using a solid phase assay (ELISA) with the N-ter or C-ter peptide, respectively, bound to the plate. The IgG-enriched input (IgG), unbound, and affinity-purified N-ter and C-ter antibodies were tested. D. The sequence of preproGATI is shown. The $\mathrm{N}$-ter and $\mathrm{C}$-ter antigenic peptides are indicated in bold (black); the identified C-ter amidation site is in red and other potential cleavage/amidation sites are in orange; paired basic cleavage sites (green), furin-like cleavage sites (blue with yellow highlight) and six potential N-glycosylation sites (-NXS/T; pink) are marked. E. Mating ectosomes (15 $\mu \mathrm{g}$ protein) were analyzed without treatment (-) or after digestion with PNGase $\mathrm{F}$ (buffer alone, $+\mathrm{B}$; with enzyme, $+\mathrm{E}$ ), revealing a reduction in molecular mass (red arrow) of the $75-\mathrm{kDa}$ C-ter product but not the $120-\mathrm{kDa} \mathrm{N}$-ter proGATI product. Digestion with neuraminidase and O-glycosidase (buffer alone, $+B$; with enzyme, $+E$ ) had no effect. The results were 


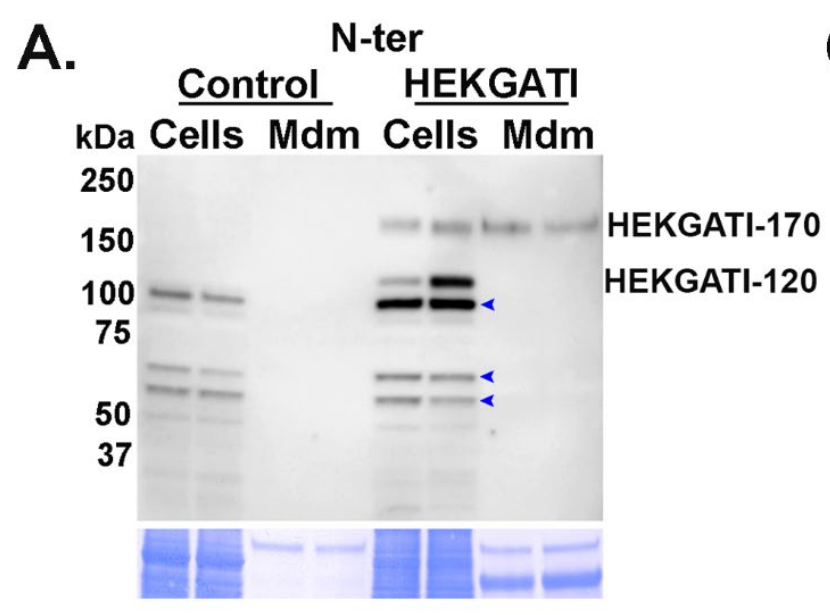

HEK-GATI

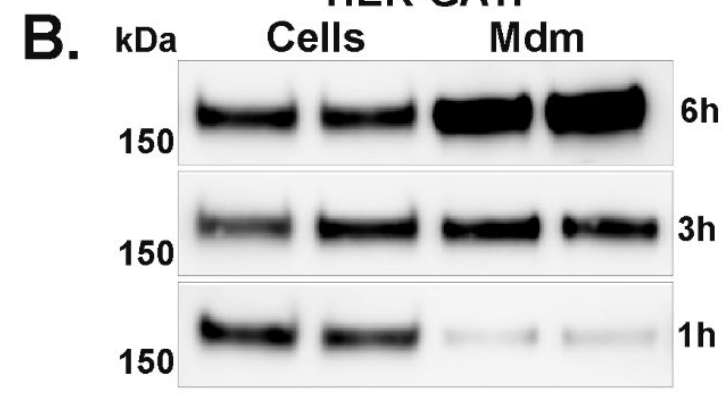

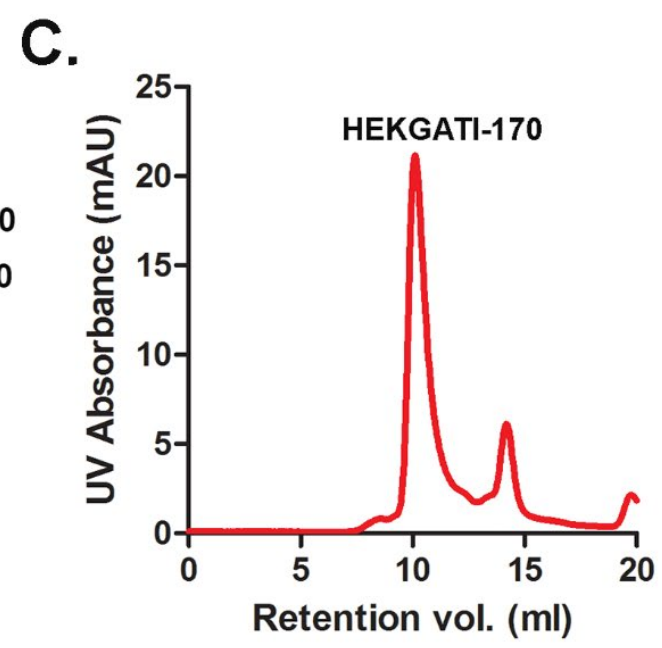

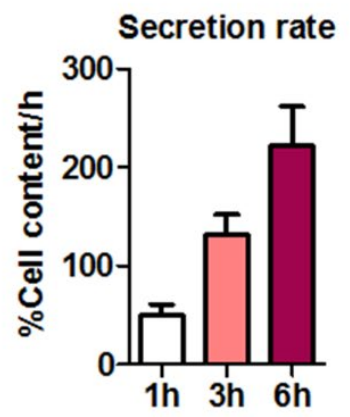

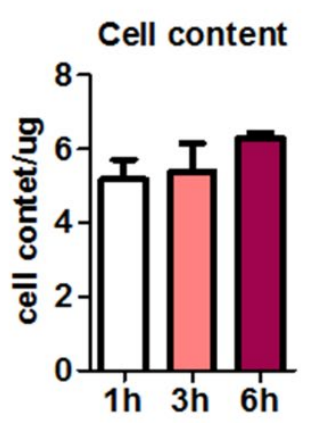

1028

1029

1030

1031

1032

1033

1034

1035

1036

1037

Figure S2. A. Cell extracts (Cells) and the spent medium (Mdm) from HEK-preproGATI cells and Control cells were probed with the N-ter proGATI antibody. HEK-proGATI protein (HEK-GATI-170) was detected in both cell lysates and spent media, while HEK-GATI-120 was only present in cell extracts. Non-specific bands (present in Control) are marked with blue arrowheads. Equal amounts of cell lysate ( $20 \mu \mathrm{g}, 10 \%$ of total) and spent medium ( $1 \%$ of total from an $18 \mathrm{~h}$ collection) were analyzed. B. HEK-GATI cells were incubated in serum-free medium for 1,3 and $6 \mathrm{~h}$ time periods; cell lysates and spent media were analyzed with the C-ter antibody. The HEK-GATI cells secrete the 170-kDa product rapidly; its secretion rate increased over a period of 6 hours (left graph), while the cell content remained constant (right graph). C. Gel filtration chromatogram of purified HEK-proGATI protein. The relative absorbance, measured at 280 $\mathrm{nm}$ (red line) shows the peak of purified HEK-proGATI protein. 


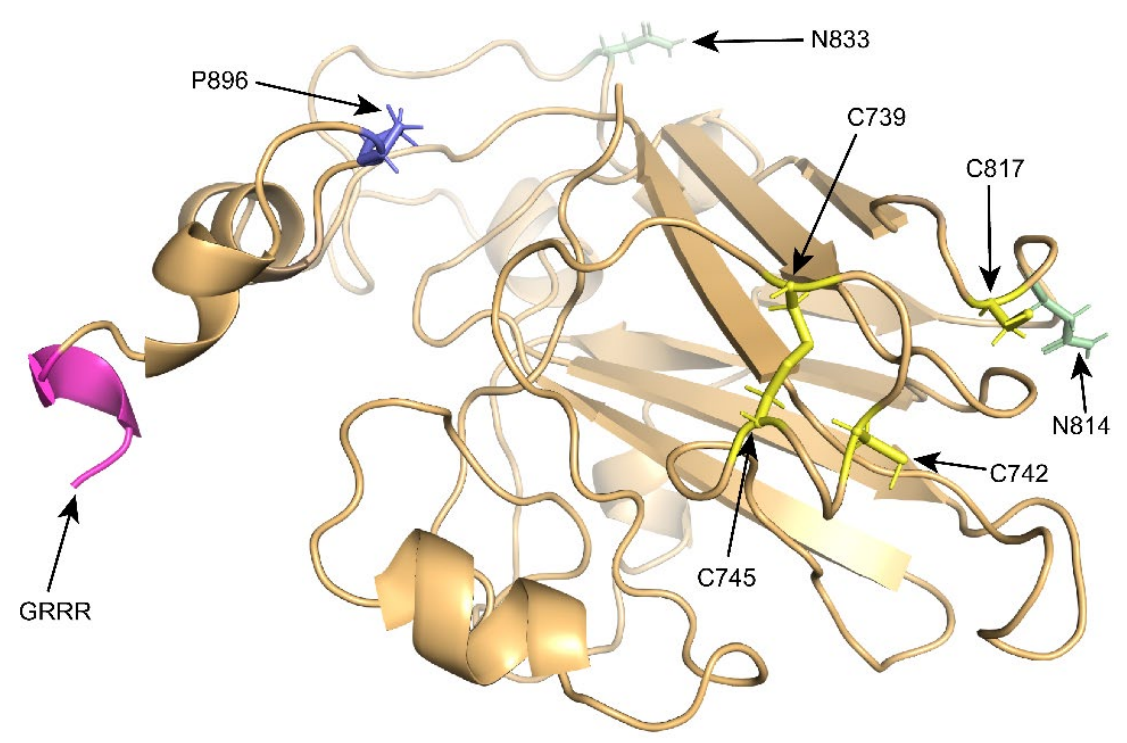

Figure S3. The detailed structural model for domain 3 of proGATI is shown. This domain forms an antiparallel $\beta$ sandwich. The post-translationally modified residues identified in purified HEK-proGATI protein are all exposed on the surface; two deamidated Asn residues (marked in green), one HyP residue (purple) and the C-terminal amidation site (pink) are indicated. This domain contains four Cys residues (indicated in yellow); two $\left(\mathrm{C}^{739}\right.$ and $\mathrm{C}^{745}$ ) are predicted to form a disulfide bond, while two others ( $\mathrm{C}^{742}$ and $\left.\mathrm{C}^{817}\right)$, although in relatively close proximity, are not.

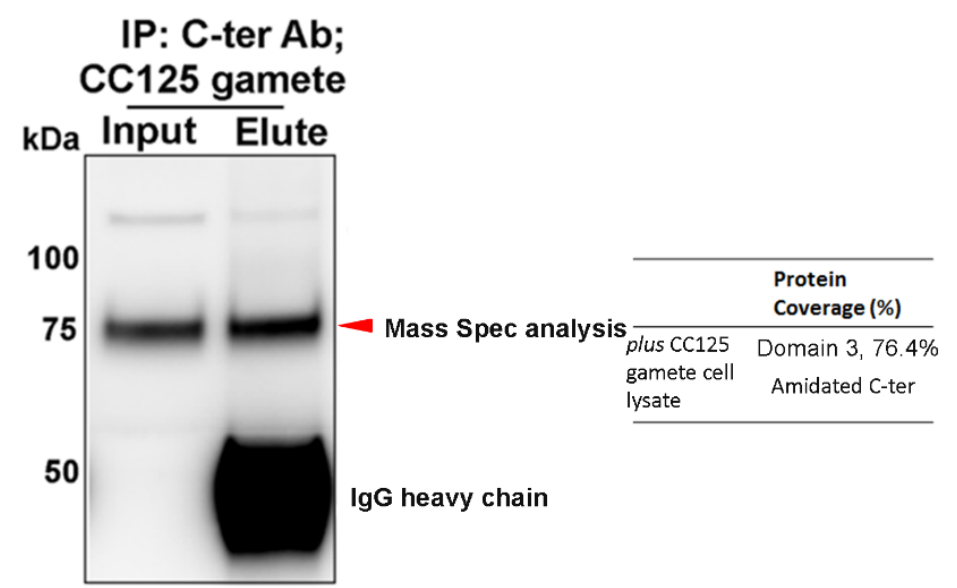

1047 Figure S4. Affinity-purified C-ter antibody was used to immunoprecipitate cross-reactive material from 1048 plus gamete cell lysates. The 75-kDa fragment (red arrowhead) was analyzed by mass spectrometry. Only peptides from the C-terminal region of proGATI were identified; all were to the C-terminal side of the 1050 furin-like cleavage site illustrated in Fig. 1E. The C-terminal peptide (VLYPNDPAAYAAYAPGTGGGATI-NH ${ }_{2}$ ) identified in plus gametes was $\alpha$-amidated. 
1053

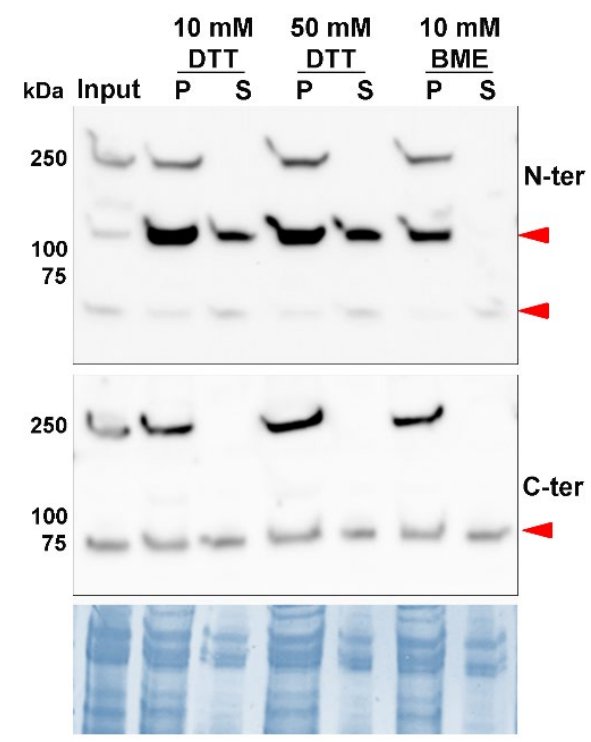

Figure S5. Isolated ectosomes (input) were washed with buffer containing either 10 or $50 \mathrm{mM}$ dithiothreitol (DTT) or $10 \mathrm{mM} \beta$-mercaptoethanol (BME). Although the $120-\mathrm{kDa} \mathrm{N}$-terminal product was released into the supernatant by DTT, it remained ectosome-associated in the presence of $\beta$ mercaptoethanol. No differential effects of these reagents were observed for the 75-kDa C-terminal fragment that is released from ectosomes by buffer treatment alone (see Fig. 6C).

Full-length processed, amidated VLE1

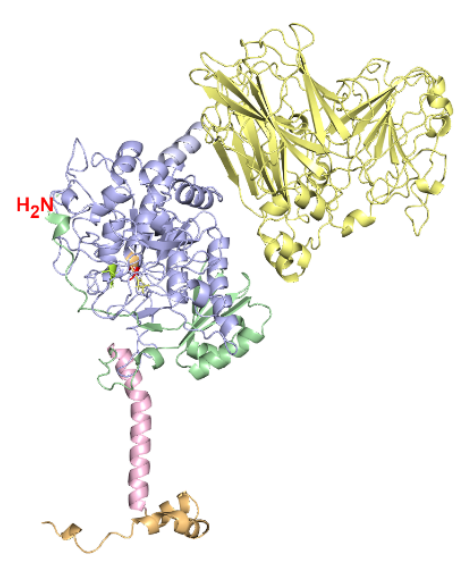

Vegetative Cell Cilia and Plus Gamete Cilia

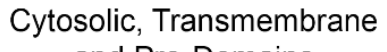
and Pro-Domains

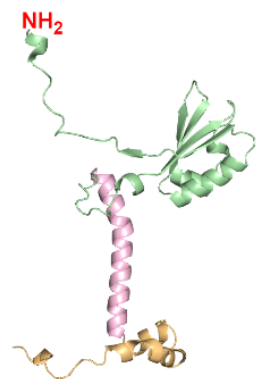

Cilia Only

\section{Catalytic and C-terminal} Domains

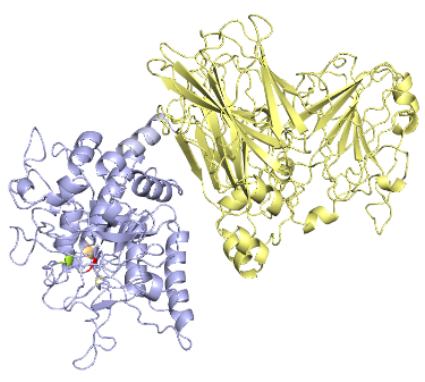

Mating Ectosomes and Soluble Secretome
1060

1061

1062

1063

1064

1065

1066

Figure S6. Changes in VLE1 domain organization occur during trafficking of VLE1 from cilia to ectosomes and the soluble secretome. When on the ciliary membrane of both vegetative cells and plus gametes, full-length VLE1 that has been cleaved at the diarginine site and subsequently amidated is present. However, as VLE1 moves to ectosomes and is released into the secretome, the catalytic S8 and C-terminal domains dissociate from the pro-domain which is not present in these fractions; the N-terminal/prodomain region is presumably either retained on the ciliary membrane or trafficked back to the cell body for degradation. 


\section{Supplemental Data}

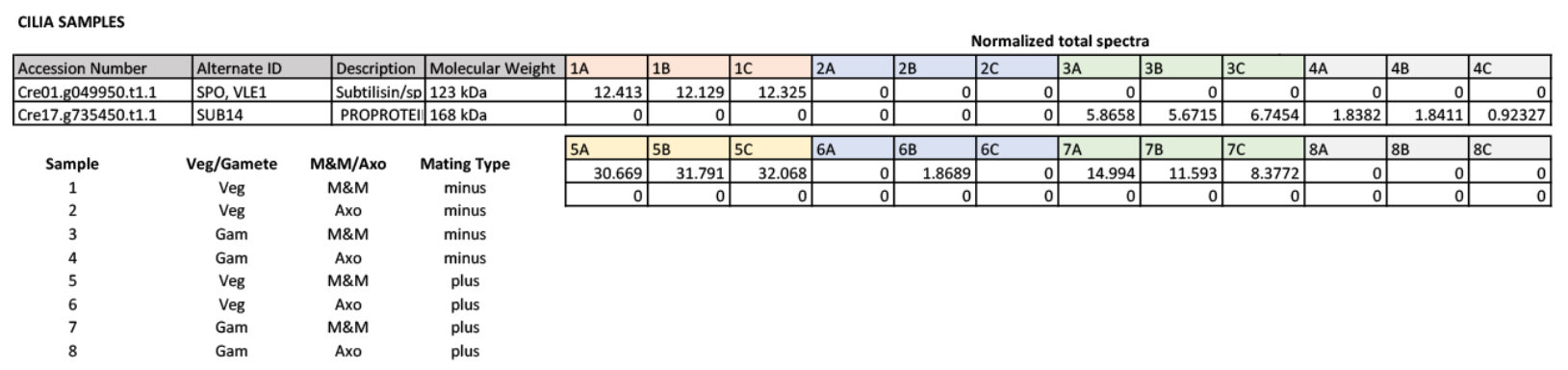

\begin{tabular}{|c|c|c|c|c|c|c|c|c|c|c|c|}
\hline \multicolumn{5}{|l|}{ MATING ECTOSOMES } & \multicolumn{7}{|c|}{ Normalized to average spectral count $(58,988)$} \\
\hline Accession Number & $\begin{array}{l}\text { Phytozome } \\
\text { Annotation }\end{array}$ & $\begin{array}{l}\text { Alternate } \\
\text { ID }\end{array}$ & Molecular Mass & $\begin{array}{c}\text { Sample } \\
\text { EA }\end{array}$ & $\begin{array}{c}\text { Sample } \\
\text { EB }\end{array}$ & $\begin{array}{c}\text { Sample } \\
\text { EC }\end{array}$ & $\begin{array}{c}\text { Sample } \\
\text { ED }\end{array}$ & $\begin{array}{c}\text { Sample } \\
\mathrm{EE}\end{array}$ & Sample EF & $\begin{array}{c}\text { Total } \\
\text { spectral } \\
\text { counts } \\
\text { (Mean) }\end{array}$ & $\begin{array}{c}\text { Relative } \\
\text { standard } \\
\text { deviation } \\
\text { (SD/ } \\
\text { Mean) }\end{array}$ \\
\hline Cre01.g049950.t1.1 & \begin{tabular}{|l} 
PROPROTEIN \\
CONVERTASE \\
SUBTILISIN/KEXIN
\end{tabular} & VLE1 & $123 \mathrm{kDa}$ & 65.8 & 45.0 & 45.0 & 56.7 & 41.3 & 46.3 & 50.0 & 0.2 \\
\hline Cre17.g735450.t1.1 & $\begin{array}{l}\text { PROPROTEIN } \\
\text { CONVERTASE } \\
\text { SUBTILISIN/KEXIN }\end{array}$ & SUB14 & $168 \mathrm{kDa}$ & 8.4 & 3.0 & 19.8 & 25.7 & 25.3 & 26.4 & 18.1 & 0.6 \\
\hline
\end{tabular}

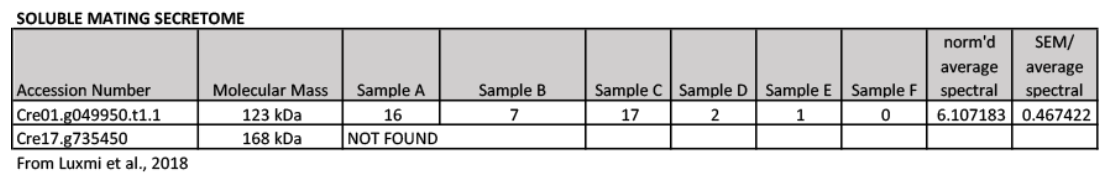

1069 Supplemental Data File 1. Mass spectral data (normalized total spectral counts) for VLE1 and SUB14 in 1070 vegetative and gametic cilia of both mating types. Cilia were fractionated into a detergent-soluble 1071 membrane plus matrix fraction and an axonemal fraction. All samples were analyzed in triplicate. Also 1072 shown are the normalized average spectral counts for the presence of these two proteins in mating 1073 ectosomes (data from (Luxmi et al., 2019)) and soluble mating secretome (data from (Luxmi et al., 2018)) 1074 (*.xlsx format).

1075

1076

\section{Source Data File}

1077 This file contains annotated uncropped gel and blot images used to prepare Figs. 1B, 1C, 1D, 2A, 2B, 2D, $10782 \mathrm{E}, 3 \mathrm{~A}, 4 \mathrm{~A}, 5 \mathrm{~B}, 5 \mathrm{D}, 5 \mathrm{E}, 6 \mathrm{~A}, 6 \mathrm{C}, \mathrm{S1A}, \mathrm{S1E}, \mathrm{S2A}, \mathrm{S2B}, \mathrm{S4}$, and S5. (*.docx format). 